\title{
Modelling of groundwater-vegetation interactions in a tidal marsh
}

\author{
Pei Xin ${ }^{1, \#}$, Jun Kong ${ }^{2}$, Ling Li ${ }^{1,2}$, D. A. Barry ${ }^{3}$
}

${ }^{1}$ National Centre for Groundwater Research and Training, School of Civil Engineering, The University of Queensland, Queensland, Australia

Emails: p.xin@uq.edu.au

1.li@uq.edu.au

${ }^{2}$ State Key Laboratory of Hydrology-Water Resources and Hydraulic Engineering, Hohai University, Nanjing, China

Email: kongjun999@126.com

${ }^{3}$ Laboratoire de technologie écologique, Institut d'ingénierie de l'environnement, Faculté de l'environnement naturel, architectural et construit (ENAC), Ecole Polytechnique Fédérale de Lausanne (EPFL), Station 2, 1015, Lausanne, Switzerland Email: andrew.barry@epfl.ch

Advances in Water Resources, accepted on 13 April 2013

\# Author to whom all correspondence should be sent. Tel: +61 7 33469820. Fax: +61 7 33653525. Email: p.xin@uq.edu.au 


\section{Abstract}

Wetting and drying due to tidal fluctuations affect soil conditions and hence plant growth in tidal marshes. Here, a coupled one-dimensional model was developed to simulate interacting groundwater flow and plant growth in these wetlands. The simulation results revealed three characteristic zones of soil conditions for plant growth along a cross-creek section subjected to the combined influences of spring-neap tides and evapotranspiration: (1) a near-creek zone affected by semi-diurnal tides over the whole spring-neap cycle, where the soil is well aerated although the plant growth could be slightly limited by the local water content dropping periodically below the wilting point on the ebb tide; (2) a less well-drained zone where drainage occurs only during neap tides (for which the daily inundation is absent) and plant growth is aeration-limited; and (3) an interior zone where evapotranspiration determines the soil-water saturation. Plant growth dynamics, which depend on these soil conditions, lead to spatial biomass distributions that are consistent with the characteristic zonation. The simulations shed light on the feedback mechanism for groundwater-vegetation interactions in the marsh system. It was demonstrated that the growth of pioneer plants can improve the soil aeration condition as a result of transpiration. The strength of this feedback varies spatially in accordance with the three characteristic zones of soil-water saturation. However, the development of another species in the marsh system is likely to be more complicated than suggested by the "positive feedback" mechanism proposed previously, due to the influence of inter-species competition. The feedback effects are generally more complex, involving both plant growth enhancement and inhibition depending on the combined influence of the intra- and inter-species competition, the ecosystem's carrying 
capacity and plant transpiration. These findings demonstrate the interplay of ecological and hydrological processes in tidal marshes, and provide guidance for future research, including field investigations that aim to establish the principle relationship between marsh morphology and plant zonation.

Key words: Salt marsh; Vegetation-groundwater interaction; Plant zonation; Tide; Soil aeration condition

\section{Highlights:}

A coupled model was developed for simulating groundwater-vegetation interactions

Simulations revealed three characteristic zones along a cross-creek marsh section

Positive feedback between groundwater and aeration-limited vegetation was demonstrated 


\section{Introduction}

Tidal marshes are complex coastal wetland systems influenced by various interacting ecological and hydrological processes $[1,8,31,49]$. Due to tides, these wetlands are periodically inundated by coastal water, which affects the marsh soil aeration $[25,29,43,48,54,56,57,59]$. Since the oxygen diffusivity and concentration in pore-water are much lower than those in the air [2], poor aeration may lead to low oxygen availability in the soil, and affect adversely marsh plant respiration and growth [1,9,10,11].

Recent numerical studies examined the tidally induced pore-water flow and associated soil aeration conditions using various models including Boussinesq equation-based models [33,56], saturated flow models [15], Richards' equation-based (saturated and unsaturated flow) models $[31,48,54,55,57,58,59]$ and air-water two-phase models $[25,45]$. These studies, which are mostly based on two-dimensional (2-D) cross-creek sections, aimed at quantifying the link between hydrological processes and vegetation dynamics in tidal marshes. Overall, they showed that, during the early stage of inundation, surface water infiltrates the soil through the marsh platform. As the tide recedes, pore water seeps out of marsh sediments through the creek bank and bottom. The asymmetric intra-tidal flow dynamics generates pore-water circulation near the creek, and thereby provides a mechanism for rapid mass (including air) exchange across the marsh soil surface [25,54]. This leads to a well aerated zone (with relatively low soil-water saturations over the tidal cycle) near the tidal creek, which may be better suited to plant development than the marsh interior. The finding is consistent with previous observations that salt marsh plants such as Spartina alterniflora often grow better near tidal creeks than in the inner areas $[20,21,30]$. 
Previous studies also postulated a "positive feedback" mechanism for groundwater-vegetation interactions in tidal marshes: Pioneer plants initially grow successfully near the creek where soil aeration is optimal. This leads to an increase in the local evapotranspiration, which in turn improves the soil aeration condition for further development of other plant species/communities $[8,25,29,32,45,48]$. If the soil's saturated hydraulic conductivity is low enough (e.g., less than $10^{-6} \mathrm{~m} / \mathrm{s}$ ), the enhanced evapotranspiration may even induce a permanently aerated zone below the soil surface in which oxygen is available for local plants $[29,45,48]$. These studies were largely based on prescribed evapotranspiration rates and simulated the water flow and soil aeration without coupling of pore-water flow and vegetation growth dynamics. So far, the interactions among pore-water flow, evapotranspiration and vegetation dynamics in marsh systems have not been modelled in detail. The hypothesized "positive feedback" mechanism warrants further exploration with consideration of different, potentially competing plant species. Most previous studies only considered soil aeration as a limiting condition for plant growth. In theory, the marsh plant growth may also be constrained by a water-limiting condition if the soil-water saturation falls below the wilting point over the tidal cycle $[41,47]$.

Groundwater-vegetation interactions have been widely investigated in various environments. In particular, Ridolfi et al. [39,40], Muneepeerakul et al. [36], Vervoort and van der Zee [50] and Ursino [47] examined such interactions in inland wetlands, where the watertable is relatively shallow and ecological processes are usually aeration-controlled. These studies, which focused on groundwater dynamics driven by rainfall events and plant transpiration, demonstrated the complexity of dynamic wetland eco-hydrology and improved 
understanding of vegetation-groundwater interactions in inland wetland systems. However, we are unaware of similar studies carried out on coastal wetlands, including tidal marshes. Unlike inland wetlands, tidal marshes are subjected to periodic wetting and drying due to tides. The tidal oscillations affect significantly the dynamics of both pore-water flow and marsh vegetation growth. Furthermore, in contrast with the stochastic rainfall condition examined previously (e.g., [36]), the tidal forcing is regular and deterministic. Yet, it remains a question whether such a forcing factor would lead to plant growth and distribution of a deterministic nature in marsh eco-systems. If so, what factors control and characterize the plant growth and distribution?

This study aimed to (1) develop a coupled model of interacting groundwater (pore-water) flow and plant growth dynamics in hypothetical tidal marshes; (2) examine groundwater-vegetation interactions in a tidal marsh under the influence of both monochromatic and dichromatic tides (i.e., spring-neap tides); and (3) explore the "positive feedback" mechanism for groundwater-vegetation interactions proposed previously $[8,25,29,32,45,48]$.

\section{Modelling methodology}

Based on the assumption of a hydrostatic pressure distribution (i.e., negligible vertical flow), Richards' equation was integrated along the vertical direction, resulting in a governing equation of local watertable with capillarity correction to simulate the pore-water flow in the marsh soil over long periods. The pore-water flow model, allowing the determination of the soil-water saturation in the plant root zone, was coupled with a vegetation growth model. The 
coupling accounts for the effect of soil-water saturation on the plant growth as well as the effect of plant transpiration on water saturation and pore-water flow in the marsh soil. The coupled model was used to simulate the vegetation development and distribution in tidal marshes under the influence of monochromatic and dichromatic tides.

\subsection{Conceptual model}

The model was based on a cross-section perpendicular to a creek with the marsh soil assumed to be homogeneous and isotropic within a rectangular domain (ABCD; Figure 1a), a model configuration that was adopted in previous studies $[29,47,56]$. AC is the marsh platform and $\mathbf{B D}$ is the impermeable base. The creek bank $\mathbf{A B}$ was assumed to be vertical, which gives a fixed (simplified) boundary for the numerical model (presented below). The boundary $\mathbf{C D}$ was placed far enough inland from the creek bank to be unaffected by tidal oscillations.

On boundary $\mathbf{A B}$, two forcing (tidal) conditions were considered with the creek water level subjected to the influence of:

Case 1, a monochromatic tide,

$$
H(0, t)=Z_{M S L}+A_{1} \cos \left(\omega_{1} t\right), \text { and }
$$

Case 2, spring-neap tides,

$$
H(0, t)=Z_{M S L}+A_{1} \cos \left(\omega_{1} t\right)+A_{2} \cos \left(\omega_{2} t+\delta\right),
$$

where $H(0, t)$ is the water level [L] in the tidal creek at the time $t[\mathrm{~T}] ; Z_{M S L}$ is the mean creek water level [L]; $A_{1}$ and $A_{2}$, and $\omega_{1}$ and $\omega_{2}$ are the amplitudes [L] and angular frequencies $\left[\mathrm{T}^{-1}\right]$ of the semi-diurnal solar and lunar tide, respectively; and $\delta$ is the phase difference between the two tidal constituents [-]. The dichromatic signals in the second case 
combine to produce the spring-neap tidal variations. For the semi-diurnal solar tide, $T_{1}=12$ $\mathrm{h}$ and $\omega_{1}=0.5236 \mathrm{rad} / \mathrm{h}$; and $T_{2}=12.42 \mathrm{~h}$ and $\omega_{2}=0.5059 \mathrm{rad} / \mathrm{h}$ for the semi-diurnal lunar tide. The spring-neap tidal cycle is formed with a longer period of $T=2 \pi /\left(\omega_{1}-\omega_{2}\right)=$ $14.78 \mathrm{~d}[18]$.

\subsection{Numerical models}

As illustrated in Figures $1 \mathrm{~b}$ and $\mathrm{c}$, the models of groundwater flow and plant growth were coupled based on the mean soil-water saturation (MSS) over the mean root depth (MRD). Groundwater dynamics was affected by tidal forcing and evapotranspiration (modelled as a sink term). The instantaneous MSS over the MRD was used to determine both the transpiration rate (plant root uptake) and marsh carrying capacity for plant growth. It should be noted that the suitability of soil conditions for plant growth in salt marshes may be underpinned by soil-water saturation, soil redox potential, pore-water salinity, sulphide concentration and soil organic content $[16,31,43,49]$. As we focused on groundwater-vegetation interactions, only soil-water saturation was considered, which is the main factor and likely to influence the behaviour of others [43].

\subsubsection{Groundwater flow dynamics}

One-dimensional Boussinesq type models have been applied widely to simulate groundwater-vegetation interactions in upland wetlands [e.g., 36,40,47,50]. As the Boussinesq equation does not account for unsaturated flow, previously the soil moisture dynamics in the unsaturated zone was simulated using a bucket-type model, assuming a uniform soil-water saturation in the vertical direction [47]. Such a representation of the unsaturated zone is likely to be inadequate for tidal marsh systems, which are often composed of fine-grained soils with 
high capillary rise $[44,56]$. Unsaturated flow is responsible for draining the shallow groundwater system in the marsh soil $[31,54,59]$. Thus, a model integrating both saturated and unsaturated flow is needed for simulation of pore-water flow in the marsh soil. For that purpose, Richards' equation was applied previously [31,54,57,59]; in 2-D, it can be written as,

$$
\frac{\partial \theta}{\partial t}=\frac{\partial}{\partial x}\left[K(\psi) \frac{\partial \Phi}{\partial x}\right]+\frac{\partial}{\partial z}\left[K(\psi) \frac{\partial \Phi}{\partial z}\right]+q
$$

where $\theta$ is the soil-water content [-], $\Phi=\psi+z[\mathrm{~L}]$ is the total hydraulic head, with $z$ being the elevation [L] based on a datum set at the marsh platform (Figure 1a) and $\psi$ being the pore water pressure head (negative in the unsaturated zone), $K(\psi)$ is the hydraulic conductivity $\left[\mathrm{LT}^{-1}\right]$ and $q$ is the source/sink term per unit area $\left[\mathrm{T}^{-1}\right]$.

Richards' equation-based models are computationally intensive and relatively complex, and unwarranted at this early stage of eco-hydrological modelling of the marsh system, particularly at large temporal and/or spatial scales. In balancing the model's sophistication and efficiency, we adopted an alternative approach using a simple yet robust model suitable for large scale ecological applications. Previous simulation results $[54,57,59]$ showed that flow in a homogeneous and isotropic marsh soil is mainly horizontal except for a short period at the beginning of inundation when vertical infiltration occurs. Thus, we neglected the vertical flow in both saturated and unsaturated zones during the marsh exposure. We further assumed that the unsaturated zone, similar to the saturated zone, is able to adjust itself to satisfy a hydrostatic pressure distribution as the watertable rises and falls. This assumption is reasonable for low-frequency forcing conditions (e.g., tides) [26].

Under the hydrostatic pressure assumption, we can relate the local pressure head ( $\psi[\mathrm{L}])$ in both the saturated and unsaturated zones to the local watertable elevation $(H[\mathrm{~L}])$ as, 


$$
\psi=H-z
$$

Note that $|H|$ is essentially the distance between the marsh platform and watertable.

Substituting equation (4) into (3) and then integrating the equation along the vertical direction, we have,

$$
\int_{-L}^{Z_{0}} \frac{\partial \theta}{\partial t} \mathrm{~d} z=\int_{-L}^{Z_{0}} \frac{\partial}{\partial x}\left[K(\psi) \frac{\partial H}{\partial x}\right] \mathrm{d} z+\int_{-L}^{Z_{0}} \frac{\partial}{\partial z}\left[K(\psi) \frac{\partial H}{\partial z}\right] \mathrm{d} z+\int_{-L}^{Z_{0}} q \mathrm{~d} z
$$

where $Z_{0}=0$ (i.e., the datum as shown Figure 1a) is the elevation of the marsh surface [L], and $-L$ is the elevation of the impermeable base [L] (i.e., $L$ is the thickness of the marsh soil layer). Evaluating the second integral on the RHS of equation (5), we have,

$$
\int_{-L}^{Z_{0}} \frac{\partial \theta}{\partial t} \mathrm{~d} z=\int_{-L}^{Z_{0}} \frac{\partial}{\partial x}\left[K(\psi) \frac{\partial H}{\partial x}\right] \mathrm{d} z+\left.K(\psi) \frac{\partial H}{\partial z}\right|_{z=Z_{0}}-\left.K(\psi) \frac{\partial H}{\partial z}\right|_{z=-L}+\int_{-L}^{Z_{0}} q \mathrm{~d} z .
$$

As the flux across the impermeable base $(z=-L)$ is zero,

$$
\left.K(\psi) \frac{\partial H}{\partial z}\right|_{z=-L}=0
$$

with

$$
\int_{-L}^{Z_{0}} q \mathrm{~d} z-\left.K(\psi) \frac{\partial H}{\partial z}\right|_{z=Z_{0}}=Q
$$

where $Q$ represents the per unit width source/sink $\left[\mathrm{LT}^{-1}\right]$, e.g., evapotranspiration. Equation (6) can thus be rewritten as,

$$
\int_{-L}^{Z_{0}} \frac{\partial \theta}{\partial t} \mathrm{~d} z=\int_{-L}^{Z_{0}} \frac{\partial}{\partial x}\left[K(\psi) \frac{\partial H}{\partial x}\right] \mathrm{d} z+Q
$$

Evaluating the integrals in equation (9) separately for the saturated and unsaturated zones yields (see Appendix A for details),

$$
\underbrace{\frac{\partial}{\partial t} \int_{-L}^{H} \phi \mathrm{d} z}_{1}+\underbrace{\frac{\partial}{\partial t} \int_{H}^{0} \theta \mathrm{d} z}_{2}=\underbrace{\frac{\partial}{\partial x} \int_{-L}^{H}\left(K_{S} \frac{\partial H}{\partial x}\right) \mathrm{d} z}_{3}+\underbrace{\frac{\partial}{\partial x} \int_{H}^{0}\left[K(\psi) \frac{\partial H}{\partial x}\right] \mathrm{d} z}_{4}+Q,
$$

where $\phi$ is the soil porosity [-] and $K_{S}$ is the saturated hydraulic conductivity [LT $\left.{ }^{-1}\right]$. In 
equation (10), terms 1 and 2 are, respectively, the changes of soil-water content in the saturated and unsaturated zones. Terms 3 and 4 are, respectively, the net fluxes across the two vertical boundaries of the saturated and unsaturated zones related to a control volume as illustrated in Figure 1c. Capillary rise, given by the soil-water retention characteristics, is typically large for marsh soils. In the case of a shallow watertable, it is nearly always truncated by the marsh platform over the tidal cycle ( $H$ close to zero) [56]. This truncation influences watertable fluctuations in shallow unconfined aquifers $[5,7,56]$, and is modelled in equation (10) since the upper limit of the integration is set to the marsh platform elevation.

For the unsaturated zone, the relationships among the soil content, relative hydraulic conductivity and suction head $(\psi<0)$ are defined using Gardner's [17] soil-water retention curves. With the residual water content $\theta_{\text {wres }}$ [-] set to zero, Gardner's [17] formulas are,

$$
\begin{aligned}
& \theta=\phi S=\phi \exp (\alpha \psi), \\
& K(\psi)=K_{S} \exp (\alpha \psi),
\end{aligned}
$$

where $S$ is the soil-water saturation [-] and $1 / \alpha$ is the mean capillary rise $\left[\mathrm{L}^{-1}\right]$. Note that these soil-water retention formulas do not take hysteresis into account. Substitution of equations (4) and (11) into equation (10) yields,

$$
\begin{aligned}
& \phi \frac{\partial H}{\partial t}-\phi \exp (\alpha H) \frac{\partial H}{\partial t} \\
& =K_{S} \frac{\partial}{\partial x}\left[(L+H) \frac{\partial H}{\partial x}\right]+K_{S} \frac{\partial}{\partial x}\left[\frac{1-\exp (\alpha H)}{\alpha} \frac{\partial H}{\partial x}\right]+Q
\end{aligned}
$$

If $\alpha$ is relatively large (e.g., for coarse-grained sand), the second terms on both the left and right hand sides of equation (12) are small, such that the effect of the unsaturated flow becomes negligible. In this case, equation (12) reduces into the classic Boussinesq equation, i.e., 


$$
\phi \frac{\partial H}{\partial t}=K_{S} \frac{\partial}{\partial x}\left[(L+H) \frac{\partial H}{\partial x}\right]+Q
$$

We neglected vertical flow in the above derivation. Vertical flow occurs mainly at the beginning of the inundation and plays a key role in recharging the marsh soil $[15,54,56,57]$. Previous studies [48,56] applied 2-D Richards' equation-based models to simulate pore-water flow in marsh soils. It was found that local marsh soils become fully saturated shortly after flooding of the marsh platform. To reflect this condition, the watertable was set to the creek water level when flooding occurs, i.e.,

$$
H(x, t)=H(0, t) \text { if } H(0, t)>Z_{0} .
$$

Based on the watertable predictions, we compared the new 1-D model based on equation (12) and the classical Boussinesq equation-based model (BEM) against results from direct simulations by a Richards' equation-based model (SUTRA [52]) and published experimental data [6]. Details are given in Appendix B.

\subsubsection{Evapotranspiration}

Evapotranspiration from a wetland system is affected by various factors, including soil moisture, solar radiation, soil heat capacity and plant type $[4,12,32]$. These factors are usually not well characterized, which hinders estimation of evapotranspiration rates $(E P \mathrm{~s})$ in real marshes. To focus on the coupling of hydrological and ecological processes in the marsh, we chose a simple and frequently used model [13], which includes only the effect of soil moisture and plant biomass. During inundation, the marsh surface is covered by surface water and evapotranspiration does not affect water balance, i.e., $E P=0$. For the period when the marsh surface is exposed, the evapotranspiration rate is given as the sum of evaporation rate ( $E$ 
$\left.\left[\mathrm{LT}^{-1}\right]\right)$ and transpiration rate (plant root uptake $\left.E_{R}\left[\mathrm{LT}^{-1}\right]\right)$, i.e.,

$$
E P=E+E_{R}
$$

The total root uptake is affected by both the plant biomass and soil-water saturation for all the plant species considered, i.e.,

$$
E_{R}=\sum \xi_{i}\left(S_{i}^{R}\right) N_{i}
$$

where $i$ refers to the species, $\xi_{i}$ is a function representing the relationship between the mean soil-water saturation and transpiration and $N_{i}$ is the biomass. $S_{i}^{R}=r_{i}^{-1} \int_{-r_{i}}^{0} S \mathrm{~d} z$ is the mean soil-water saturation over the mean root depth $r_{i}[\mathrm{~L}]$, as illustrated in Figures 1a and c. As the roots of marsh plants (e.g., Spartina alterniflora) are typically densely distributed over the depth $r_{i}[34,42], S_{i}^{R}$ provides a link between the hydrological and ecological models. Depending on the soil-water saturation and plant biomass, the root uptake may be less than or equal to the potential transpiration rate, $E_{i}^{\max }\left[\mathrm{LT}^{-1}\right]$, i.e. [13],

$$
\xi_{i}\left(S_{i}^{R}\right)=E_{i}^{\max } \mathbf{F}_{i}
$$

where $\mathbf{F}_{i}$ is defined by a stepwise linear function (shown in Figure 2a), varying between

$W_{i}^{r} \quad[-]$ and $W_{i}^{a} \quad[-]$, which are respectively the wilting point and anaerobiosis point for species $i$. As discussed earlier, the groundwater table is relatively shallow in a tidal marsh; and thus the anoxic stress may affect mainly plant photosynthesis, in which case the anaerobiosis point becomes the dominant threshold, and influences plant root respiration and growth.

The evaporation rate $(E)$ was set to a constant in the simulations for the purpose of simplicity, neglecting variations due to changes of weather and other environmental conditions. With $E$ and $E_{R}$ combined, the evapotranspiration rate was incorporated in equation 
(12) as a sink $(Q)$ to simulate the corresponding water loss.

\subsubsection{Plant growth dynamics}

Following Muneepeerakul et al. [36] and Ursino [47], plant growth was simulated using the Lotka-Volterra model $[28,51]$, with the carrying capacity dependant on the mean soil-water saturation over the mean root depth $\left(S_{i}^{R}\right)$,

$$
\frac{\partial N_{i}}{\partial t}=N_{i} G_{i} \frac{\mathbf{L}_{i}\left(S_{i}^{R}\right)-\beta_{i, i} N_{i}-\beta_{i, j} N_{j}}{C_{i}}-M_{i} N_{i}+D_{i} \frac{\partial^{2} N_{i}}{\partial x^{2}},
$$

where $G_{i}$ and $\mathbf{L}_{i}$ are, respectively, the intrinsic growth rate $\left[\mathrm{T}^{-1}\right]$ and carrying capacity for species $i ; \beta_{i, i}$ is the coefficient for intra-species competition and $\beta_{i, j}$ is the coefficient for inter-species competition with species $j \quad$ (two species were considered in this study); $M_{i}$ is the mortality rate due to plant decay $\left[\mathrm{T}^{-1}\right] ; D_{i}$ is the coefficient of seed diffusion $\left[\mathrm{L}^{2} \mathrm{~T}^{-1}\right]$; and $C_{i}[\mathrm{~L}]$ is the limiting coefficient of the carrying capacity due to the influence of other environmental factors (e.g., light, nutrient, temperature, etc.). In this study, the carrying capacity was described by a step function of the mean soil-water saturation over the mean root depth (shown in Figure 2b),

$$
\mathbf{L}_{i}=\left\{\begin{array}{cc}
1 & \text { if } \quad W_{i}^{r} \leq S_{i}^{R} \leq W_{i}^{a}, \\
0 & \text { otherwise. }
\end{array}\right.
$$

It is worth noting that a constant intrinsic growth rate was used in the present study but the carrying capacity varied with the MSS over the MRD under the influence of tides. Therefore, the actual plant growth rate varied both temporally and spatially, depending on the local tidally driven groundwater dynamics. 


\subsubsection{Model solution}

A semi-implicit, central finite-difference scheme was applied to solve equation (12) for the watertable elevation $(H)$ with the transpiration rate calculated based on the computed saturation profile from the previous time step. Equation (18) for plant biomass $(N)$ was solved separately using the Euler method with the carrying capacity calculated also based on the computed saturation profile from the previous time step. The truncation error associated with the Euler method accumulates over time. However, the global truncation error (GTE) for a fixed-time simulation is proportional to $\Delta t[3]$, i.e.,

$$
\mathrm{GTE} \leq \frac{\Delta t M}{2 C_{L}}\left[\exp \left(C_{L} T\right)-1\right]
$$

where $M$ is an upper bound on the second-order derivative of $N$ (biomass) over the simulation period $(T)$ and $C_{L}$ is the Lipschitz constant of the first-order derivative of $N$. In theory, equation (20) can be used to determine the appropriate value of $\Delta t$ to achieve a pre-set error tolerance. In the current study, the simulation time was $145 \mathrm{~d}$ and a small $\Delta t$ $(0.1 \mathrm{~h})$ was used to ensure an acceptable accuracy of the solution for plant biomass. This cumulative error could also affect the watertable solution due to the coupling through transpiration. Therefore, we conducted a series of simulations with time step and grid sizes reduced consecutively to examine the convergence of the numerical solutions for both plant biomass and watertable elevation. The difference between two consecutive solutions was found to diminish (less than $0.5 \%$ ) as the grid and time step sizes decreased, i.e., solutions becoming independent of both sizes (i.e., converged). 


\subsection{Boundary and initial conditions}

The initial conditions were determined according to the surface water level at the high-high tide, i.e., $H(x, 0)=Z_{M S L}+A_{1}+A_{2}$. The boundary $\mathbf{C D}$ was set at $x=200 \mathrm{~m}$ and treated as a no-flow boundary (numerical tests showed that, at this distance, the tidal effect was negligible). As the creek bank was vertical, the effect of a seepage face was negligible $[33,46]$. Therefore, the watertable exit point at the bank edge was assumed to be coupled with the tidal water level in the creek. As discussed earlier, when the marsh surface gets flooded, the watertable elevation was assumed to equal the surface water level, i.e., $H(x, t)=H(0, t)$ for $H(0, t)>0$.

In reality, animals, stochastic environmental factors and soil properties may lead to a complex, random plant biomass distribution prior to the growth season. Here, to elaborate the feedback mechanism between vegetation and groundwater through simulations, the initial plant biomasses of the modelled two species were assumed to be uniformly distributed across the marsh section with both $N_{1}$ and $N_{2}$ set to 0.2 . It can be seen from equation (18) that, as the plant biomass increases, so too does the intra- and inter- species competition in which case plant growth is inhibited. The effects of initial biomass distributions on the simulation results are examined through a sensitivity analysis in Section 4.

\subsection{Parameters values used in the simulations}

Sandy loam, a typical soil type encountered in tidal marshes with a relatively high permeability, was used as the simulated marsh soil [44]. Following [53], the saturated hydraulic conductivity, $K_{S}$, was set to $1.23 \times 10^{-5} \mathrm{~m} / \mathrm{s}$ with porosity $\phi=0.41$. The mean capillary rise was taken as $1 \mathrm{~m}$, i.e., $\alpha=1 \mathrm{~m}^{-1}$, and the thickness of the marsh soil layer $L$ 
as $5 \mathrm{~m}$. For the monochromatic tide (Cases 1), the amplitude of semi-diurnal solar tide $A_{1}$ was set to $1 \mathrm{~m}\left(A_{2}=0\right)$. For the spring-neap tides (Cases 2$)$, the amplitudes of semi-diurnal solar and lunar tides were set to $0.25 \mathrm{~m}\left(A_{1}\right)$ and $0.75 \mathrm{~m}\left(A_{2}\right)$, respectively. The phase difference between the two tidal constituents was set to zero $(\delta=0)$. The mean creek water level, $Z_{M S L}$, was set to $-0.8 \mathrm{~m}$, which allowed, in both cases (Cases 1 and 2), the marsh platform to be inundated with a water depth of $0.2 \mathrm{~m}$ at the high or high-high tide.

Observed evapotranspiration rates for wetlands vary greatly from site to site [29]. Here, we set the evaporation rate at $E=2 \mathrm{~mm} / \mathrm{d}$ and potential transpiration rates of the two plants $E_{1}^{\max }=E_{2}^{\max }=6 \mathrm{~mm} / \mathrm{d}$ (during the marsh surface exposure). The maximum potential evapotranspiration rate was thus $8 \mathrm{~mm} / \mathrm{d}$ (when the total biomass equals 1 ), which is typical of coastal salt marshes [29].

The transpiration rate $(\mathbf{F})$ and carrying capacity $(\mathbf{L})$ were described using the step functions shown in Figure 2. Two species were considered: Species 1 was assumed to prefer a relatively high soil-water saturation condition with the wilting point $\left(W_{1}^{r}\right)$ and anaerobiosis point $\left(W_{1}^{a}\right)$ set to 0.45 and 0.95 , respectively; Species 2 was supposed to be more adapted to a lower soil-water saturation condition with $W_{2}^{r}=0.2$ and $W_{2}^{a}=0.7$.

Here, we focus on the soil-water saturation effect on the plant growth and thus assumed that the effects of other environmental factors in equation (18) were negligible, i.e., $C_{i}=1$ for both species. Seed diffusion $\left(D_{i}\right)$ was neglected. Plant decay was also neglected in the initial simulations for one growth season but was incorporated in longer period simulations to examine the effect of the initial conditions on the equilibrium state of the marsh system. The intrinsic growth rates were set to: $G_{1}=G_{2}=10^{-7} \mathrm{~s}^{-1}$. Although these growth rates affect the 
time taken for the model to reach an equilibrium state, numerical simulations suggested that the characteristic behaviour of the plant growth and underlying mechanism remain unchanged. For the saturation-tolerant Species 1, the mean root depth was assumed to be deeper and set at $r_{1}=0.4 \mathrm{~m}[36,47]$, while the roots of Species 2 were assumed to be distributed within a shallower soil layer with $r_{2}=0.2 \mathrm{~m}$. These conditions were consistent with the different transpiration modulation functions set for the two species. For the intra-species and inter-species competitions, we assumed that the competition extent coefficients for both were the same.

For all simulations, the time step $\Delta t$ was set to $0.1 \mathrm{~h}$ with $\Delta x=0.2 \mathrm{~m}$ as the grid size. These sizes were found to be small enough to affect little the numerical solutions. The results predicted by the model with these time step and grid sizes were very close to those based on $\Delta t=0.05 \mathrm{~h}$ and $\Delta x=0.1 \mathrm{~m}$ (relative difference less than $0.5 \%$ ). The simulation results presented here can thus be considered as "converged" numerical solutions.

\section{Simulation results and discussion}

In order to examine in detail the tidal effect and feedback between groundwater and vegetation, the growth of both modelled plant species was simulated independently in $§ 3.1$ and $\$ 3.2$, i.e., no inter-species competition was included $\left(\beta_{1,1}=\beta_{2,2}=1\right.$ and $\left.\beta_{1,2}=\beta_{2,1}=0\right)$. Plant decay $\left(M_{i}\right)$ was also neglected in these simulations covering only a single plant growth season. Following these investigations, simulations incorporating both intra- and inter-species competitions were conducted, with results presented in $\S 3.3$. 


\subsection{Tidal effects}

\section{Monochromatic tide (Case 1)}

Simulated watertable fluctuations and associated variations of the MSS (mean soil-water saturation) over the MRD (mean root depth) for Species 1 are, respectively, shown in Figures $3 \mathrm{a}$ and $3 \mathrm{~b}$ for Case 1 . Under the simulated condition, the marsh platform was subjected to tidal inundation twice a day, each for a period of $\sim 2.4 \mathrm{~h}$ during which the marsh soil was fully saturated (Figure 3b). As the creek water level declined on the receding tide, drainage of pore water to the creek occurred, lowering the watertable particularly in the near-creek zone (e.g., $x$ $=1 \mathrm{~m})$. Due to the soil damping effect, the drainage weakened from the creek to the marsh interior. These trends are similar to previous results $[48,56]$. Corresponding to the watertable fluctuation, the MSS over the MRD fluctuated in a similar fashion (Figure 3b). In the near-creek zone (e.g., $x=1 \mathrm{~m})$, the MSS dropped below the anaerobiosis point (0.95) shortly after the marsh platform became exposed, providing a suitable condition for plant growth (Figure 3c). This condition remained as the MSS continued to drop with the receding tide until falling below the wilting point (0.45). The switch to a water-limiting condition (with MSS below the wilting point) occurred only in the area near the creek (not evident at $x=5 \mathrm{~m}$ ). In the marsh interior $(x=10$ and $15 \mathrm{~m}$ ), the watertable remained close to the marsh surface over the tidal cycle with high MSS above the anaerobiosis point (Figures 3a and b), resulting in a condition inhibiting plant growth (Figure 3c). On the rising tide, the watertable rose with the creek water level and became coupled with the tide once the platform was inundated. Overall, the watertable fluctuations exhibited asymmetry with a rapid rising phase followed by a slow falling phase over the semi-diurnal cycle, similar to the watertable behaviour due to 
non-linear tidal wave propagation in an unconfined coastal aquifer [22,27].

To examine further the soil condition for plant growth, we calculated the periods within the tidal cycle when conditions were, respectively, air-limiting (MSS above the anaerobiosis point), water-limiting (MSS below the wilting point) and suitable (MSS between the two thresholds) for plant growth within the root zone of Species 1 (Figure 4a). These periods obviously changed with time due to increased transpiration as the plant grew (i.e., "positive feedback"). However, the changes were relatively small as shown in the next section and the results plotted in the figure from the early time simulation can be considered as representative. The air-limiting condition persisted in the root zone across the marsh section for relatively long periods and increasingly affected the area from the near-creek to the marsh interior, indicating the important role played by soil aeration in controlling plant growth. Next to the creek (between $x=0$ and $2 \mathrm{~m}$ ), where the air-limiting condition was a minimum (i.e., optimal aeration), the plant growth was instead stressed by some periods of limited water availability. The combination of these two limiting conditions resulted in optimal conditions for plant growth, which occurred not immediately next to the creek but at a distance $(x=2 \mathrm{~m})$ corresponding to the location where the near-creek, water-limiting condition diminished. Beyond this point, the growth condition was fully controlled by the soil aeration, which deteriorated towards the marsh interior with the growth period reduced to zero for $x>6.4 \mathrm{~m}$.

The simulated plant growth corresponded well to the conditions discussed above (Figure 4b). The plant biomass distribution across the marsh section followed closely the variations of the growth period given by the complement of the combined periods of air- and water-limiting conditions. This result is expected because the total plant growth rate over the tidal cycle is 
approximately proportional to the growth period multiplied by the constant carrying capacity described by the step function used in the simulation. In reality, the carrying capacity would vary gradually with the soil-water saturation during transitions from limiting to suitable-for-growth conditions (instead of sharp changes described by the step function). This would lead to some modification of the plant growth rate; however, the growth period is likely to remain a key factor in controlling the plant growth dynamics and distribution.

Obviously, the plant growth characteristics depend on the plant species. To explore this dependence, we compared results for Species 2 (Figures $4 c$ and d) with those of Species 1 (Figures $4 \mathrm{a}$ and $\mathrm{b}$ ). Overall, the trends were similar between the two species. However, two major differences were evident, due to the tolerance of Species 2 to the relatively low soil-water saturation condition: (1) with a lower wilting point, Species 2 experienced the water-limiting condition in a much narrower area next to the creek. This led to a large shift of the optimal growth location toward the creek. (2) Due to a lower anaerobiosis point, the growth-inhibited area for Species 2 expanded towards the creek, resulting a narrower plant growth zone (between $x=0$ and 4.4 m c.f. $x=0$ and $6.4 \mathrm{~m}$ for Species 1 ).

Spring-neap tides (Case 2)

Simulations were also conducted to examine the characteristics of groundwater-vegetation interactions in the marsh system under the influence of spring-neap tides (Case 2). The results show that during the spring tides (day 0-3), temporal variations of the local watertable and MSS were essentially similar to those simulated for the monochromic tidal case (Figures 5a and 5b based on Species 1): Flooding of the marsh platform occurred twice a day and left the poorly drained marsh interior $(x=10$ and $15 \mathrm{~m})$ saturated up to the 
soil surface, resulting in an air-limiting condition that prohibited plant growth. In the area near the creek $(x=1 \mathrm{~m}$ and $5 \mathrm{~m})$, pore-water drainage on the falling tide led to lowering of the local watertable with MSS dropping below the anaerobiosis point over each spring tidal cycle, providing a suitable condition for plant growth (Figure $5 \mathrm{c}$ with enlargement). Similar to the monochromatic tidal case, the MSS in the near-creek area could drop below the wilting point on the falling tide, resulting in a water-limiting condition that inhibited plant growth.

As the tidal regime changed from spring to neap (day 4 to 7.5 ), the range of tidal creek water level fluctuations decreased and ceased to inundate the marsh platform (Figure 5a). Over this period, the cumulative effect of drainage and evapotranspiration, not interrupted by daily inundation, led to a gradual decline of the watertable in the marsh interior, resulting in an MSS below the anaerobiosis point and hence suitable conditions for plant growth (Figures $5 \mathrm{a}$ and $\mathrm{b} ; x=10$ and $15 \mathrm{~m})$. This represents a fundamental difference between the spring-neap tidal system and monochromatic tidal system. In the near-creek area, the watertable and MSS also responded to the change of the tidal regime and variations of the tidal range. This response can be seen in Figure 5c. The plant growth in the area near the creek exhibited oscillations corresponding to variations of the soil-water saturation across the growth range (between the anaerobiosis and wilting points) over both the semi-diurnal and semi-lunar (spring-neap) cycles. The growth oscillations at the semi-diurnal frequency decayed rapidly with the distance away from the creek, similar to the attenuation of the semi-diurnal tidal watertable fluctuations. As discussed above, the soil condition in the marsh interior only responded to the combined effect of drainage and evapotranspiration during neap tides when the marsh remained exposed. Thus, the local plant growth showed considerable oscillations 
over the semi-lunar cycle but not the semi-diurnal period.

To examine the spatial variations of the soil conditions, we also computed the portions of air-limiting period, water-limiting period and plant growth period over the spring-neap cycle (Figure 6a; results shown for Species 1). Again, these periods changed slightly with time due to increased transpiration as the plants grew and the results shown in the figure were based on the early time simulation. The calculated air-limiting period appeared to reveal three characteristic zones across the salt marsh section: (1) a near-creek zone with a rapidly improved aeration condition towards the creek (i.e., rapidly decreased air-limiting period), where drainage occurred on the falling tide over every semi-diurnal tidal cycle; (2) a less aerated zone clearly separated from zone 1 by a discontinuity in the slope of the curve, where drainage, at rates decreasing towards the interior, occurred only during the neap tides with no inundation of the marsh platform; and (3) an inner zone influenced little by the tides and with a relatively poor but constant aeration condition largely due to evapotranspiration also during the exposure of the marsh platform over neap tides. These spatial variations in soil aeration are different from those in the monochromatic tide case. In particular, the marsh interior under the influence of spring-neap tides was no longer wholly air-limited for plant growth (Species 1).

Periods of plant growth were predominantly determined by soil aeration, i.e., growth period $=$ total period - air-limiting period, except for a small water-limited area next to the creek (i.e., MSS dropped below the wilting point for some periods). As a result, the growth period first increased with distance from the creek, and peaked at the location where the water-limiting condition ceased (Figures 6a and c). Growth periods then decreased with 
distance from the creek. The total plant growth rate over the spring-neap cycle followed this trend closely, producing a plant biomass distribution with the same trend (Figure 6b). For Species 2, both the anaerobiosis point and wilting point were lower than for Species 1. Consequently, the water-limited near-creek zone narrowed significantly (Figure 6c versus Figure 6a). Moreover, the reduction of the soil-water saturation in the interior due to evapotranspiration during neap tides was insufficient for the moisture content to reduce below the anaerobiosis point for plant growth (Figures $6 \mathrm{c}$ and $\mathrm{d}, x>23 \mathrm{~m}$ ).

It is worth noting that the simulations assumed an instantaneous response by the plant to changes of the soil condition. However, how quickly the marsh plants respond to changing environmental conditions remains an important question [9,38]. Under flooded conditions with low oxygen availability in the soil, the functioning of plant roots would be affected rapidly [38]. For example, the stomata of flood-intolerant plants usually close shortly after the soil is flooded [24], which inhibits the plant growth. To explore the sensitivity of the results to the assumed plant response, we conducted simulations with the total plant growth calculated over the semi-diurnal cycle using carrying capacities determined based on the tidally averaged MSS. In this way, the plant was assumed to respond to the average soil condition over the semi-diurnal tidal cycle $(12 \mathrm{~h})$. The results showed differences mainly in the near-creek area (Figure 7a). While the MSS could vary both above the anaerobiosis point and below the wilting point with the tide, the averaged MSS over the tidal cycle remained between these two points in this area. If the plant only responded to the tidally averaged MSS, it would grow all the time. Despite this difference for the near-creek area, the overall soil condition, plant growth dynamics and plant biomass distribution were similar to those from the simulations 
based on the assumption of an instantaneous plant response (Figure $6 \mathrm{~b}$ versus Figure $7 \mathrm{~b}$ ). This suggests that the simulated behaviour and trend of the marsh system, such as the three characteristic zones for the soil condition and plant growth, may represent an important aspect of marsh eco-hydrology under the combined influence of spring-neap tides and evapotranspiration.

\subsection{Feedback effects}

As discussed above, the near-creek zone possessed the optimal soil aeration condition for pioneer plant development. Previous studies $[8,25,29,45,48]$ proposed that, as a result of the pioneer plant growth, the increase in evapotranspiration may, in turn, improve the soil aeration condition for further development of other plant communities. In the following, we examine this positive feedback mechanism.

The interrelationship between the mean soil-water saturation (MSS over the MRD) and the biomass for Species 1 over the simulation period (10 spring-neap tidal cycles) is shown in Figure 8 for five locations across the marsh section. It is evident that the MSS oscillated within and outside the range suitable for plant growth (indicated by the green vertical lines in the Figure 8 plots). Such oscillations varied characteristically with the distance from the creek. The MSS oscillations near the creek $(x=0$ and $1 \mathrm{~m})$ contained both semi-diurnal and semi-lunar signals, with the former being dominant. Towards the interior, the dominant signals switched. The MSS condition for plant growth also changed from being predominantly water-limiting (near the creek) to air-limiting (in the interior). We described in the previous section the dynamic response of plants to these soil conditions. Here, our interest is on the long-term interrelationship between the MSS and plant growth (biomass). 
For that purpose, a linear function was fitted to the biomass amount versus MSS (blue lines in Figure 8). The fitted lines for all locations showed negative slopes (e.g., $\overline{\mathrm{d} S_{1}^{R} / \mathrm{d} N_{1}}$ $<0$ ), indicating a long-term trend of decreasing soil-water saturation as a result of plant growth. Note that we also plotted the slopes $\left(\overline{\mathrm{d} S_{2}^{R} / \mathrm{d} N_{1}}\right)$ for "Species 2 " (not considered in the simulation) to examine the effect of Species 1 on the suitability of soil conditions for "other species". These slopes shown in Figure 9 varied spatially. $\overline{\mathrm{d} S_{1}^{R} / \mathrm{d} N_{1}}$ started from nearly zero at the creek bank and decreased to a minimum around $x=20 \mathrm{~m}$. Afterwards, it increased to a constant level at $x=60 \mathrm{~m}$ and remained at this level for $x>60 \mathrm{~m}$.

The variations of the feedback strength as indicated by the magnitude of the slope are due to the completing influence of tides and evapotranspiration on the soil-water saturation. In the area immediately next to the creek, semi-diurnal tides play a dominant role and the evapotranspiration effect is negligible; thus, the feedback of the plant growth via transpiration on the soil-water saturation is rather weak. Further from the creek, the effect of semi-diurnal tides weakens; conversely, transpiration and hence the plant growth feedback become increasingly important. This trend continues until a minimum feedback slope (maximum feedback strength) is reached at a critical distance related to the wavelength (propagation distance, $\lambda_{1}$ ) of the semi-diurnal tidal watertable fluctuations [37],

$$
\lambda_{1}=\sqrt{\frac{2 K_{S} L}{n_{e} \omega}} .
$$

where $n_{e}$ is the effective soil porosity [-]. Based on the simulation results, we suggest that this critical distance equals $\chi_{1} \lambda_{1}\left(=20 \mathrm{~m}\right.$, with $\chi_{1}=13.9 \mathrm{~m}$ and assuming $\left.n_{e}=\phi\right)$. Note that equation (21) is based on a simple groundwater wave theory [37], and the proportionality factor and hence the critical distance may depend on the pioneer plant species. Further from 
the creek, the plant growth becomes much more constrained by the increasingly poor soil aeration condition due to limited drainage during neap tides only and hence induces less feedback on the soil-water saturation. Beyond another critical distance related to the propagation of spring-neap tidal watertable fluctuations $\left(\chi_{2} \lambda_{2}=\chi_{2} \sqrt{2 K_{S} L / n_{e} \omega^{*}}\right.$ with $\omega^{*}$ being the frequency of the spring-neap tidal watertable fluctuations), the soil condition and plant growth become fully controlled by the evapotranspiration, leading to a constant feedback magnitude (i.e., constant slope). Again based on the simulation results, we estimated the second critical distance $\left(\chi_{2} \lambda_{2}\right)$ as $60 \mathrm{~m}$ with $\chi_{2}=7.7$. It is interesting to note that the curve representing the effect of Species 1 on the MSS over the (shallower) MRD of "Species 2" was lower than that based on the MSS over the MRD of Species 1. This suggests that the feedback affected more significantly the plants with shallow root zones. In any case, the feedback relationship between the MSS and plant biomass varied across the marsh section, displaying three characteristic zones as evident in the soil conditions for plant growth (Figure $6 a)$.

These results support partially the "positive feedback" mechanism proposed by previous studies $[8,25,29,32,45,48]$. However, the area mostly impacted by the positive feedback is not immediately next to the creek but at a distance that corresponds to the wavelength of the semi-diurnal tidal watertable fluctuations. Because the tidal marsh system studied here is typically air-limited, pioneer plants are expected to increase evapotranspiration, thereby lowering the soil-water saturation and improving the soil aeration. It has been suggested that pioneer plants developing near the creek may also loosen the rhizosphere soil, increasing the soil hydraulic conductivity $\left(K_{S}\right)$ and reducing the capillary effect (increased $\alpha$ ) [25]. Such 
changes of soil properties are likely to improve further soil aeration giving rise to improved plant growth (details in Section 4).

\subsection{Effects of species competition}

In the simulations discussed above, we simulated the growth of the two modelled plant species independently and considered only the intra-species competition with the growth rates set at $G_{1}=G_{2}=10^{-7} \mathrm{~s}^{-1}$. After 10 spring-neap tidal cycles ( $148 \mathrm{~d}$, equivalent to a growing season), the marsh system did not reach an equilibrium state, with local biomass remaining less than the maximum plant biomass $(=1)$ that is expected for the equilibrium under the condition of no mortality. It was demonstrated that pioneer plants can improve the local soil aeration condition. In this section, we examine if other plant species can benefit from improved soil aeration by simulating the growth of two competing plant species.

To better elucidate how inter-species competition combines with intra-species competition to affect the plant growth dynamics, we simulated the growth of the two species with a higher intrinsic growth rate, i.e., $G_{1}=G_{2}=10^{-6} \mathrm{~s}^{-1}$ (ten times that used above). In this way, the plants would grow more quickly to incur significant species competition. For comparison, we also ran simulations with only intra-species competition considered (in which case the growth of both plant species was simulated independently). The results of predicted local biomass plotted in Figure 10 showed that, with only the intra-species competition included, the plant grew to the system's maximum capacity with the biomass reaching unity across much of the marsh section. Note the stepwise growth pattern in the interior where growth occurred only during the neap tides (e.g., $x=25 \mathrm{~m}$ in Figure 10a), in contrast with the continuous, fluctuating growth in the near-creek zone (e.g., $x=2 \mathrm{~m}$ in Figure 10a). 
With the inter-species competition included, the growth of both species became constrained across the whole marsh section (Figures 10c and d). With only the intra-species competition included, Species 1 grew more quickly at $x=2 \mathrm{~m}$ than at $x=5$ and $25 \mathrm{~m}$ (Figure 10a). This trend, however, was reversed in the simulation with the inter-species competition included. The relatively large constraint on the growth of Species 1 at $x=2 \mathrm{~m}$ was due to the competition by Species 2, which, with lower anaerobiosis and wilting points, was more readily adapted to the relatively well drained soil condition in the area next to the creek (Figure 10b). The biomass of Species 1 at $x=2 \mathrm{~m}$ increased with time to a steady, maximum level of 0.50 , lower than that at $x=5 \mathrm{~m}(0.54)$ and $x=25 \mathrm{~m}(0.57)$. This was consistent with the model prediction that the inter-species competition favoured Species 2 in the area very close to the creek, where the mean soil-water saturation was relatively low (Figure 10a).

Without the inter-species competition, the increased growth rates $\left(G_{1}=G_{2}=10^{-6} \mathrm{~s}^{-1}\right)$ did not change the spatial biomass distributions of both species for early times prior to local biomass reaching the maximum level (Figures 11a and b), which essentially showed similar patterns to those for the base case with $G_{1}=G_{2}=10^{-7} \mathrm{~s}^{-1}$ (Figures 6a and c). The capping effect due to the system's maximum carrying capacity altered these biomass distributions in the later part of the growth season. For Species 1, a relatively uniform distribution with biomass reaching unity across the whole marsh section was achieved. For Species 2, while the plant biomass gradually increased to the maximum level in the near-creek area, the marsh interior remained unsuitable for plant growth. The inclusion of inter-species competition in the simulation led to significant changes in the predicted spatial biomass distributions for both species at all times (Figures 11c and d). Overall, Species 1 appeared to be disadvantaged 
vis-à-vis Species 2 in the near-creek zone. This competing effect is evident in Figure 12 where the biomass of both species was plotted at various locations over the growth season. In the near-creek area (Figure 12a), the soil was well drained with relatively low water content, favouring the growth of Species 2. Thus, Species 2 dominated over Species 1 (curve above the 1-1 line with slope > 1). In the marsh interior, the much wetter soil condition favoured Species 1 (Figure 12e). Between the creek and interior was a transition zone (Figures 12b and c) where neither species had any advantage over the other, i.e., the biomass was distributed evenly between the two species with a curve slope of about unity. The average biomass distribution between the two species across the whole marsh section was also examined. The results show that the marsh overall favoured the more water-tolerant species (Species 1), reflecting the relatively high moisture content. The inter-species competition further assisted the dominance of Species 1 within the whole marsh section (Figure 12f).

Under the influence of the inter-species competition, the small-scale spatial variations of biomass for both species also differed significantly from the cases without such competition. These variations were characterized by large changes of spatial growth patterns (i.e., spatial derivative of the biomass). In the cases without inter-species competition, such variations reflected the local optimum and minimum growth conditions for the species themselves (Figures $11 \mathrm{a}$ and $\mathrm{b}$ ) and three characteristic points of variations could be identified (e.g., $x=0$, 2 and $6.5 \mathrm{~m}$ for Species 1 in Figure 11a). The inter-species competition introduced interactions between the two species. A local optimal growth condition for one species would inhibit the growth of the other species and vice versa. This led to increased variations of local growth patterns; in particular, more characteristic points of variations were evident in each 
case of either Species 1 or 2 . At these points, the competition between the two species was accentuated.

In summary, the results suggest that while a pioneer plant (e.g., Species 1) can improve the local soil aeration condition as shown in $\S 3.2$, the development of another species (e.g., Species 2) in the marsh system is likely to be more complicated than suggested by the "positive feedback" mechanism due to the influence of inter-species competition. At the early growth stage with only a small amount of biomass, inter-species competition is negligible and thus the improved soil aeration can positively affect the development of other plants. However, the impact of inter-species competition would become critically important as biomass accumulates in the system. This is then likely to lead to more complex feedback effects involving growth enhancement and inhibition, depending on the combined influence of the intra- and inter- species competitions, ecosystem carrying capacity and plant transpiration characteristics.

\section{Sensitivity analyses}

Focusing on the equilibrium state of the marsh ecosystem, we conducted sensitivity analyses to assess the importance of marsh platform elevation, soil hydraulic conductivity and capillary rise in modulating the vegetation-groundwater interactions. For that purpose, the decay was simulated with $D_{1}=D_{2}=G_{1} / 10$ and the model was run for sufficiently long time (100 spring-neap tidal circles) to reach an equilibrium state. Numerical checks showed that the initial conditions did not affect the equilibrium state. The biomass at the equilibrium state fluctuated slightly over the spring-neap tidal circle, but the tidally averaged value was constant. In the following, we will focus on the simulated biomass distribution at the 
equilibrium state.

\subsection{Importance of marsh topography (relative marsh platform elevation)}

Salt marshes are a vulnerable ecosystem as they act as a transitional zone between tidal water and uplands [14]. Considering the global warming scenario, if the sediment deposition rate cannot match the speed of sea level rise, the marsh platform elevation may become lower with respect to the mean sea level and hence the creek water level, resulting longer inundation periods [23].

We conducted further simulations with different marsh platform elevations relative to the mean creek water level $\left(Z_{M S L}\right)$. By raising $Z_{M S L}$, a situation of a relatively low platform elevation was created and vice versa. The decrease in the relative platform elevation worsened the soil aeration condition across the creek section. This led to contraction of the growth zones for Species 1 and 2 (Figures 13a and b). The plants disappeared in the marsh interior. As the elevation declined to $-0.3 \mathrm{~m}$, Species 2 could not even survive in the near-creek zone (Figure 13b). On the contrary, an increase in the marsh platform elevation led to expansion of the growth zones for both species. In the near-creek zone, soil with increased aeration favoured Species 2, the growth of which competed against and inhibited the growth of Species 1 . These results suggest that if the marsh elevation does not increase commensurately with the sea level rise, (1) the overall productivity of aeration-dependent plants would decrease; (2) anoxia-tolerant plants such as Species 1 may replace other, less anoxia-tolerant species; and (3) the area of bare flats may increase as vegetation growth ceases due to the adverse soil aeration in the marsh interior. An increase in bare flats would in turn reduce sediment deposition and may accelerate the relative sea level rise. 


\subsection{Importance of soil hydraulic conductivity}

As discussed earlier, the roots of the pioneer plants can soften and loosen the rhizosphere soil, which increases the soil hydraulic conductivity. As the hydraulic conductivity increases, the extent of tidal influence on the marsh soil conditions expands (equation (21)). This may lead to improved soil aeration, particularly in the marsh interior.

As expected, the growth zones of both Species 1 and 2 expanded towards the marsh interior with increased soil hydraulic conductivity (Figures $13 \mathrm{c}$ and d). It is interesting that the near-creek zone dominated by Species 2 (i.e., with Species 1 inhibited) also expanded due to increased soil drainage and aeration. Relatively speaking, the increase in soil hydraulic conductivity is likely to favour less anoxia-tolerant plants. If pioneer plants are anoxia-tolerant with relatively high anaerobiosis and wilting points, their growth in the near-creek area may lead to conditions with increased soil hydraulic conductivity through loosening the rhizosphere soil, which can disadvantage the plants themselves in further development - creating a "negative feedback" mechanism.

\subsection{Importance of capillary rise}

A large capillary rise height leads to a thick, poorly-aerated high-saturation zone, which can inhibit the development of Species 2. This may lead to the disappearance of the species, as simulated with $\alpha=0.5 \mathrm{~m}^{-1}$ (Figure 13f). For Species 1, the growth zone also contracted as the capillary rise increased. However, this contraction only occurred in the near-creek zone (Figure 13e). The unsaturated zone was very shallow away from the creek (between $x=20$ and $30 \mathrm{~m}$ ), so the local saturation changed only slightly with the increased capillary rise height, which did not result in noticeable changes in the biomass of Species 1. 
Capillary effects can be weakened by developments of roots and macro-pores (e.g., crab burrows). With a lower capillary rise height $\left(\alpha=2 \mathrm{~m}^{-1}\right)$, the soil-water saturation near the creek decreased, favouring Species 2 over Species 1 (Figures 13e and f).

\section{Conclusions}

Tidal marshes are important coastal wetlands with complex ecohydrology. Previous investigations on vegetation-groundwater interactions did not explore directly the link between the plant growth and soil condition as controlled by groundwater flow. In the present study, we developed a coupled model that incorporates the effect of soil-water saturation on the plant growth as well as the effect of plant transpiration on groundwater flow in the marsh soil to enable simulations of interacting plant growth and groundwater flow in tidal marshes.

This model was applied to simulate marsh plant growth subject to the influence of monochromatic and dichromatic tides. The findings from the study, as summarised below, may have important implications for better understanding of the marsh eco-hydrology:

(1) The simulations revealed three characteristic zones across the marsh section perpendicular to the tidal creek in terms of soil conditions for plant growth: a near-creek zone affected by semi-diurnal tides over the whole spring-neap cycle, where the soil is well aerated but the plant growth may be slightly limited by local water content dropping below the wilting point on the falling tides; a less well drained zone where drainage occurs only during the neap tides (when the daily inundation is absent) and plant growth is aeration-limited; and an interior zone where the evapotranspiration determines the soil-water saturation and plant growth is further limited by the poor soil aeration condition. These zones as demonstrated in Figure 6 may be linked to plant 
zonation in marsh systems.

(2) The simulations shed light on the "positive feedback" mechanism proposed previously $[8,25,29,32,45,48]$. It was demonstrated that the growth of pioneer plants can improve the soil aeration condition as a result of plant transpiration. The strength of this feedback varies spatially in accordance with the three characteristic zones of soil-water saturation. However, the improvement of soil aeration may not lead to enhanced development of other plant species simply as suggested by the "positive feedback" mechanism. Such development is likely to be more complicated, due to the influence of inter-species competition. The feedback effects are generally more complex, involving both plant growth enhancement and inhibition depending on the combined influence of the intra- and inter-species competitions, ecosystem carrying capacity and characteristics of plant transpiration.

(3) Predicting the evolution of tidal marshes is an important task in assessing the response of these wetland systems to sea level rise associated with global climate change. A plant growth model based on inundation depth [35] is often used to determine the plant biomass productivity, which is further linked to other dynamic models to simulate the sedimentation process [23]. The present study demonstrates the importance of coupling plant growth with groundwater flow in the marsh soil in predicting the marsh vegetation dynamics. Even under the same inundation condition (e.g., the hydroperiod did not change along the cross-creek section simulated here), soil aeration condition varies significantly with the distance from the creek, resulting in variations of local biomass.

(4) The sensitivity analysis showed the importance of marsh topography, soil hydraulic 
conductivity and capillary rise in modulating the vegetation-groundwater interactions in the marsh system. All these factors were found to affect the plant zonation, particularly at the equilibrium state. Therefore, in a real marsh where local topography variations and soil heterogeneity commonly exist, the plant zonation is expected to be more complex than seen here.

Tidal marshes are complex eco-hydrological systems, subjected to the influence of various stochastic and deterministic factors. This study was based on a 1-D model of a cross-creek marsh section with a flat platform. In reality, more complex marsh topography, particularly with creek networks embedded, would affect significantly the pore-water flow in the marsh soils and add further complications to the plant dynamics. To understand better the spatial distribution of marsh plants, a 2-D horizontal modelling framework, capable of representing spatial marsh morphological variations over a range of scales, is needed. Tidal marshes are also affected by strong surface water and groundwater interactions driven particularly by tides [59]. For a large-scale marsh system, surface water flow would need to be further integrated to simulate the interplay of surface water and groundwater flow in controlling the plant growth.

In this study, the ecosystem's carrying capacity for a plant species was assumed to depend solely on the soil-water saturation, with other factors such as soil salinity neglected. However, quantification of the carrying capacity based on multiple factors remains an important area for future research. Laboratory experiments and field investigations on plant growth under the influence of various factors are needed not only for establishing fundamental kinetics of plant growth but also for validating the predictions of vegetation-groundwater interactions by 
coupled models such as the one presented here. Moreover, stochastic factors such as rainfall events and soil heterogeneity (neglected here) would combine to generate complex variability in the behaviour of the marsh system and hence large degree of uncertainty in the model predictions of such behaviour. As the marsh soil undergoes periodic drainage and wetting, hysteresis in soil-water retention may also be important. Notwithstanding these complexities, the present study highlights the important role of tides in controlling the plant growth and distribution in tidal marshes. The effects and mechanisms presented here have the potential to guide future investigations, particularly those designed to understand the relationship between marsh morphology and plant zonation under the influence of tides.

\section{Appendix A. Equation derivation}

The integral on the left hand side of equation (9) can be evaluated as follows,

$$
\begin{aligned}
& \int_{-L}^{Z_{0}} \frac{\partial}{\partial t} \theta \mathrm{d} z=\int_{-L}^{H} \frac{\partial}{\partial t} \theta \mathrm{d} z+\int_{H}^{Z_{0}} \frac{\partial}{\partial t} \theta \mathrm{d} z \\
& =\frac{\partial}{\partial t} \int_{-L}^{H} \phi \mathrm{d} z-\phi \frac{\partial H}{\partial t}+\phi_{z=-L} \frac{\partial(-L)}{\partial t}+\frac{\partial}{\partial t} \int_{H}^{Z_{0}} \theta \mathrm{d} z+\theta_{z=H} \frac{\partial H}{\partial t}-\theta_{z=Z_{0}} \frac{\partial Z_{0}}{\partial t} .
\end{aligned}
$$

We assume that at the interface between the saturated and unsaturated zones $(z=H)$, the change in soil property is negligible, i.e., $\theta=\phi$. Thus,

$$
\theta_{z=H} \frac{\partial H}{\partial t}-\phi \frac{\partial H}{\partial t}=0 .
$$

Equation (A1) becomes,

$$
\int_{-L}^{Z_{0}} \frac{\partial}{\partial t} \theta \mathrm{d} z=\frac{\partial}{\partial t} \int_{-L}^{H} \phi \mathrm{d} z+\frac{\partial}{\partial t} \int_{H}^{Z_{0}} \theta \mathrm{d} z
$$

The first term on the right hand side of equation (9) is evaluated as follows, 


$$
\begin{aligned}
\int_{-L}^{Z_{0}} \frac{\partial}{\partial x}\left[K(\psi) \frac{\partial H}{\partial x}\right] \mathrm{d} z & =\int_{-L}^{H} \frac{\partial}{\partial x}\left(K_{S} \frac{\partial H}{\partial x}\right) \mathrm{d} z+\int_{H}^{Z_{0}} \frac{\partial}{\partial x}\left[K(\psi) \frac{\partial H}{\partial x}\right] \mathrm{d} z \\
= & \frac{\partial}{\partial x} \int_{-L}^{H}\left(K_{S} \frac{\partial H}{\partial x}\right) \mathrm{d} z-\left.K_{S} \frac{\partial H}{\partial x}\right|_{z=H} \frac{\partial H}{\partial x} \\
& +\frac{\partial}{\partial x} \int_{H}^{Z_{0}}\left[K(\psi) \frac{\partial H}{\partial x}\right] \mathrm{d} z+\left.K(\psi) \frac{\partial H}{\partial x}\right|_{z=H} \frac{\partial H}{\partial x} \\
& -\left.K(\psi) \frac{\partial H}{\partial x}\right|_{z=Z_{0}} \frac{\partial Z_{0}}{\partial x} .
\end{aligned}
$$

Likewise, assuming $K(\psi)=K_{S}$ at $z=H$, we have,

$$
-\left.K_{S} \frac{\partial H}{\partial x}\right|_{z=H} \frac{\partial H}{\partial x}+\left.K(\psi) \frac{\partial H}{\partial x}\right|_{z=H} \frac{\partial H}{\partial x}=0 .
$$

As $Z_{0}=0,\left.K(\psi) \frac{\partial H}{\partial x}\right|_{z=Z_{0}} \frac{\partial Z_{0}}{\partial x}=0$, and equation (A4) becomes,

$$
\int_{-L}^{Z_{0}} \frac{\partial}{\partial x}\left[K(\psi) \frac{\partial H}{\partial x}\right] \mathrm{d} z=\frac{\partial}{\partial x} \int_{-L}^{H}\left(K_{S} \frac{\partial H}{\partial x}\right) \mathrm{d} z+\frac{\partial}{\partial x} \int_{H}^{0}\left[K(\psi) \frac{\partial H}{\partial x}\right] \mathrm{d} z .
$$

Substituting equations (A3) and (A6) into equation (9) yields equation (10).

\section{Appendix B. Validation of groundwater model}

Experimental data [6] and a Richards' equation-based model (SUTRA, see $[52,56]$ for the detailed model setup) were used to validate the present groundwater flow model. In [6], 2-D groundwater flow was measured in a uniform, sandy aquifer with a simple rectangular geometry (9-m long and 1.5-m high). The sand was well sorted with a median grain size of $0.2 \mathrm{~mm}$, mean soil hydraulic conductivity, $K_{S}$, of $4.7 \times 10^{-4} \mathrm{~m} / \mathrm{s}, \phi=0.32$ and $\alpha=2 \mathrm{~m}^{-1}$. The groundwater flow was driven by a sinusoidal signal as follows (the datum was set at the aquifer base, with $t$ measured in second),

$$
H(0, t)=1.094+0.235 \sin \left(\frac{2 \pi t}{772}\right)
$$

It is worth noting that the experiment included capillary rise truncation by the sediment 
surface.

The influence of vertical flow is characterized by the non-dimensional number: $\phi \omega L / K_{S}$ [56], which took the value of six for the experimental setup, indicating relatively weak vertical flow. The present model predicted similar fluctuation ranges of the watertable to those measured in the laboratory experiment (Figure A1). With the capillary effect neglected, the model based on the classical Boussinesq equation (BEM) under-predicted the range of watertable fluctuations.

As there are no data available for cases with higher $\phi \omega L / K_{S}$ values, we compared the 1-D models with SUTRA. Two additional cases were conducted with $K_{S}$ set to $4.7 \times 10^{-5}$ $\mathrm{m} / \mathrm{s}$ and $4.7 \times 10^{-6} \mathrm{~m} / \mathrm{s}$, respectively ( $\alpha=1 \mathrm{~m}^{-1}$ in both cases). Results showed that, with $\phi \omega L / K_{S}=60$ (reflecting increased vertical flow), the present model reproduced reasonably well the watertable fluctuations simulated by SUTRA and significantly outperformed the BEM. When $\phi \omega L / K_{S}=600$, both the present model and BEM failed to reproduce the watertable fluctuations predicted by SUTRA, but the former still performed better.

The present study was based on a sandy-loam salt marsh. The $\phi \omega L / K_{S}$ value for the simulations conducted was 24, within the applicable range of the model. For salt marshes of fine-grained silt loam (e.g., $K_{S}<10^{-6} \mathrm{~m} / \mathrm{s}$ ), $\phi \omega L / K_{S}$ is likely to be on the order of hundred [56]. For this case, the vertical flow in both saturated and unsaturated zones would be significant. The effect of air-phase flow may also be important $[25,45]$. Moreover, these marshes tend to be highly compressible [19], in which case the soil compressibility needs to be considered in modelling the pore-water flow in the marsh soil [58]. These aspects would 
limit the application of the present model and requires further model development.

\section{Acknowledgments}

This research was supported by the National Basic Research Program of China (973 Program, 2012CB417005) and the Australian Research Council (DP0988718). P. X. acknowledges an Early Career Researcher Grant provided by The University of Queensland (603275). The authors acknowledge valuable comments from the reviewers, which led to significant improvement of the paper. 


\section{References}

[1] Armstrong W. Waterlogged soils. In Environmental Plant Ecology, 2nd edn, Etherington JR (ed). John Wiley: Hoboken, NJ, USA; 1982.

[2] Armstrong W, Drew M. Root growth and metabolism under oxygen deficiency. In:

Waisel EA, Kafkafi Y, eds. Plant roots: The hidden half. New York, New York, USA: Marcel Dekker, 2002.

[3] Atkinson KA. An introduction to numerical analysis (2nd ed.), New York, USA: John Wiley \& Sons, ISBN 978-0-471-50023-0, 1989.

[4] Bartholomeus RP, Witte JPM, van Bodegom PM, van Dam JC, Aerts R. Critical soil conditions for oxygen stress to plant roots: Substituting the Feddes-function by a process-based model. Journal of Hydrology 2008; 360(1-4):147-165.

[5] Cardenas MB. Lessons from and assessment of Boussinesq aquifer modeling of a large fluvial island in a dam-regulated river. Advances in Water Resources 2010; 33(11):1359-1366.

[6] Cartwright N, Nielsen P, Dunn S. Water table waves in an unconfined aquifer: Experiments and modeling. Water Resources Research 2003; 39(12), 1330, doi:10.1029/2003WR002185.

[7] Cartwright N, Nielsen P, Li L. Experimental observations of watertable waves in an unconfined aquifer with a sloping boundary. Advances in Water Resources 2004; 27(10):991-1004.

[8] Chapman VJ. Salt Marshes and Salt Deserts of the World. Leonard Hill, London, UK; 1960. 
[9] Colmer TD, Flowers TJ. Flooding tolerance in halophytes. New Phytologist 2008; 179(4):964-974.

[10] Colmer TD, Pedersen O, Wetson AM, Flowers TJ. Oxygen dynamics in a salt-marsh soil and in Suaeda maritima during tidal submergence. Environmental and Experimental Botany 2013; in press, doi:10.1016/j.envexpbot.2012.07.002.

[11] Dacey JWH, Howes BL. Water uptake by roots controls water table movement and sediment oxidation in short Spartina marsh. Science 1984; 224(4648):487-489.

[12] Drexler JZ, Snyder RL, Spano D, Paw U KT. A review of models and micrometeorological methods used to estimate wetland evapotranspiration. Hydrological Processes 2004; 18(11):2071-2101.

[13] Feddes RA, Kowalik P, Jaradny H. Simulation of Field Water Use and Crop Yield. Simulation Monographs. PUDOC, Wageningen, The Netherlands; 1978.

[14] Fitzgerald DM, Fenster MS, Argow BA, Buynevich IV. Coastal impacts due to sea-level rise. Annual Review of Earth and Planetary Sciences 2008; 36:601-647.

[15] Gardner LR. Role of geomorphic and hydraulic parameters in governing pore water seepage from salt marsh sediments. Water Resources Research 2005; 41(7), W07010, doi:10.1029/2004WR003671.

[16] Gardner LR. Comment on "Spatial organization and ecohydrological interactions in oxygen-limited vegetation ecosystems" by Marco Marani et al. Water Resources Research 2009, 45, W05603, doi:10.1029/2007WR006165.

[17] Gardner WR. Some steady state solutions of unsaturated moisture flow equations to applications to evaporation from a water table. Soil Science 1958; 85(4):228-232. 
[18] Godin G. The Analysis of Tides, University of Toronto Press: Toronto, Ontario, Canada; 1972.

[19] Hemond HF, Fifield JL. Subsurface flow in salt marsh peat: A model and field study. Limnology and Oceanography 1982; 27(1):126-136.

[20] Howes BL, Goehringer DD. Porewater drainage and dissolved organic carbon and nutrient losses through the intertidal creekbanks of a New England salt marsh. Marine Ecology Progress Series 1994; 114(3):289-301.

[21] Howes BL, Howarth RW, Teal JM, Valiela I. Oxidation-reduction potentials in a salt marsh: Spatial patterns and interactions with primary production. Limnology and Oceanography 1981; 26(2):350-360.

[22] King JN, Mehta AJ, Dean RG. Analytical models for the groundwater tidal prism and associated benthic water flux. Hydrogeology Journal 2010; 18(1): 203-215.

[23] Kirwan ML, Murray AB. A coupled geomorphic and ecological model of tidal marsh evolution. Proceedings of the National Academy of Sciences of the United States of America 2007; 104(15):6118-6122.

[24] Kozlowski TT. Plant responses to flooding of soil. Bioscience 1984; 34(3):162-167.

[25] Li HL, Li L, Lockington D. Aeration for plant root respiration in a tidal marsh. Water Resources Research 2005; 41(6), W06023, doi:10.1029/2004WR003759.

[26] Li L, Barry DA, Parlange J-Y, Pattiaratchi CB. Beach water table fluctuations due to wave run-up: Capillarity effects. Water Resources Research 1997; 33(5):935-945.

[27] Li L, Barry DA, Pattiaratchi CB. Numerical modelling of tide-induced beach water table fluctuations. Coastal Engineering 1997; 30(1-2):105-123. 
[28] Lotka A. Elements of Physical Biology. Williams and Wilkins, Baltimore, Maryland, USA; 1925.

[29] Marani M, Silvestri S, Belluco E, Ursino N, Comerlati A, Tosatto O, Putti M. Spatial organization and ecohydrological interactions in oxygen-limited vegetation ecosystems. Water Resources Research 2006; 42(6), W06D06, doi:10.1029/2005WR004582.

[30] Mendelssohn IA, McKee KL, Patrick WH. Oxygen deficiency in Spartina alterniflora roots: Metabolic adaptation to anoxia. Science 1981; 214(4519):439-441.

[31] Moffett KB, Gorelick SM, McLaren RG, Sudicky EA. Salt marsh ecohydrological zonation due to heterogeneous vegetation - groundwater - surface water interactions. Water Resources Research 2012; 48, W02516, doi:10.1029/2011WR010874.

[32] Moffett KB, Wolf A, Berry JA, Gorelick SM. Salt marsh-atmosphere exchange of energy, water vapor, and carbon dioxide: Effects of tidal flooding and biophysical controls. Water Resources Research 2010; 46, W10525, doi:10.1029/2009WR009041.

[33] Montalto FA, Parlange J-Y, Steenhuis TS. A simple model for predicting water table fluctuations in a tidal marsh. Water Resources Research 2007; 43, W03439, doi:10.1029/2004WR003913.

[34] Morris JT. Pathways and controls of the carbon cycle in salt marshes. In The Ecology and Management of Wetlands, Hooks DD (ed). Croom Helm, London, UK, 497-510; 1988.

[35] Morris JT, Sundareshwar PV, Nietch CT, Kjerfve B, Cahoon DR. Responses of coastal wetlands to rising sea level. Ecology 2002; 83(10):2869-2877. 
[36] Muneepeerakul CP, Miralles-Wilhelm F, Tamea S, Rinaldo A, Rodriguez-Iturbe I. Coupled hydrologic and vegetation dynamics in wetland ecosystems. Water Resources Research 2008; 44, W07421, doi:10.1029/2007WR006528.

[37] Parlange J-Y, Stagnitti F, Starr JL, Braddock RD. Free-surface flow in porous media and periodic solution of the shallow-flow approximation. Journal of Hydrology 1984; 70(1-4):251-263.

[38] Pezeshki SR. Wetland plant responses to soil flooding. Environmental and Experimental Botany 2001; 46(3):299-312.

[39] Ridolfi L, D’Odorico P, Laio F. Effect of vegetation-water table feedbacks on the stability and resilience of plant ecosystems. Water Resources Research 2006; 42, W01201, doi:10.1029/2005WR004444.

[40] Ridolfi L, D’Odorico P, Laio F. Vegetation dynamics induced by phreatophyte-aquifer interactions. Journal of Theoretical Biology 2007; 248(2):301-310.

[41] Rodriguez-Iturbe I. Ecohydrology: A hydrologic perspective of climate-soil-vegetation dynamics, Water Resources Research 2000; 36(1):3-9.

[42] Schubauer JP, Hopkinson CS. Above- and belowground emergent macrophyte production and turnover in a coastal marsh ecosystem, Georgia. Limnology and Oceanography 1984; 29(5):1052-1065.

[43] Silvestri S, Defina A, Marani M. Tidal regime, salinity and salt marsh plant zonation. Estuarine, Coastal and Shelf Science 2005; 62(1-2):119-130.

[44] Simonini P, Cola S. Some pore pressure measurements at the marsh of S. Felice in the Venice lagoon, in Scientific Research and Safeguarding of Venice, CORILA Research 
Program 2001 Results, Ist. Veneto di Sci. Lett. ed Arti, Venice, Italy; 2002.

[45] Tosatto O, Belluco E, Silvestri S, Ursino N, Comerlati A, Putti M, Marani M. Reply to comment by L. R. Gardner on "Spatial organization and ecohydrological interactions in oxygen-limited vegetation ecosystems,". Water Resources Research 2009; 45, W05604, doi:10.1029/2007WR006345.

[46] Turner I. Water table outcropping on macro-tidal beaches: A simulation model. Marine Geology 1993; 115(3-4): 227-238.

[47] Ursino N. Modeling biomass competition and invasion in a schematic wetland. Water Resources Research 2010; 46, W08503, doi:10.1029/2009WR008280.

[48] Ursino N, Silvestri S, Marani M. Subsurface flow and vegetation patterns in tidal environments. Water Resources Research 2004; 40(5), W05115, doi:10.1029/2003WR002702.

[49] Vernberg FJ. Salt-marsh processes: A review. Environmental Toxicology and Chemistry 1993; 12(12):2167-2193.

[50] Vervoort RW, van der Zee SEATM. Stochastic soil water dynamics of phreatophyte vegetation with dimorphic root systems. Water Resources Research 2009; 45, W10439, doi:10.1029/2008WR007245.

[51] Volterra V. Variazone e fluttuazini del numero d'individui in specie animali conviventi. Mem. Accad. Lincei, 6, 1926.

[52] Voss, C.I., Provost, A.M., 2008. A model for saturated-unsaturated, variable-density ground-water flow with solute or energy transport, U.S. Geological Survey. Water-Resources Investigations Report 02-4231 
(http://water.usgs.gov/nrp/gwsoftware/sutra.html, last accessed 4 April 2013).

[53] Wang Z, Feyen J, Nielsen DR, van Genuchten MTh. Two phase flow infiltration equations accounting for air entrapment effects. Water Resources Research 1997; 33(12):2759-2767.

[54] Wilson AM, Gardner LR. Tidally driven groundwater flow and solute exchange in a marsh: Numerical simulations. Water Resources Research 2006; 42(1), W01405. doi:10.1029/2005WR004302.

[55] Wilson AM, Morris JT. The influence of tidal forcing on groundwater flow and nutrient exchange in a salt marsh-dominated estuary. Biogeochemistry 2012; $1(1-3): 27-38$.

[56] Xin P, Gibbes B, Li L, Song Z, Lockington D. Soil saturation index of salt marshes subjected to spring-neap tides: A new variable for describing marsh soil aeration condition. Hydrological Processes 2010; 24(18):2564-2577.

[57] Xin P, Jin G, Li L, Barry DA. Effects of crab burrows on pore water flows in salt marshes. Advances in Water Resources 2009; 32(3):439-449.

[58] Xin P, Kong J, Li L, Barry DA. Effects of soil stratigraphy on pore-water flow in a creek-marsh system. Journal of Hydrology 2012; 475: 175-187.

[59] Xin P, Yuan L.-R, Li L, Barry DA. Tidally driven multiscale pore water flow in a creek-marsh system. Water Resources Research 2011; 47, W07534, doi:10.1029/2010WR010110. 


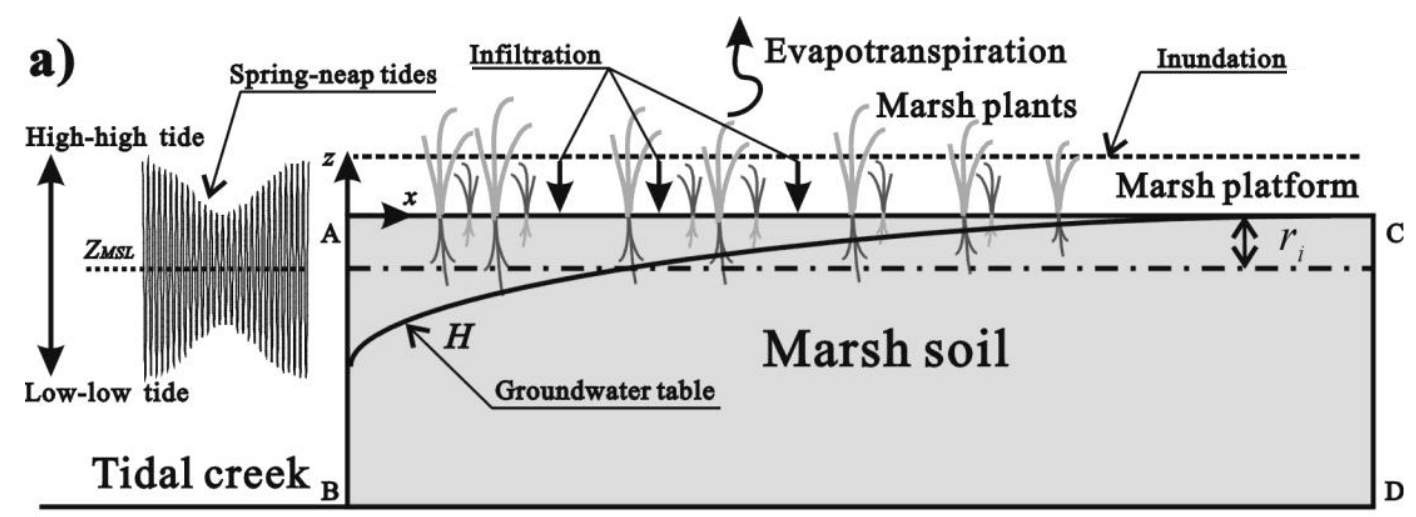

b)
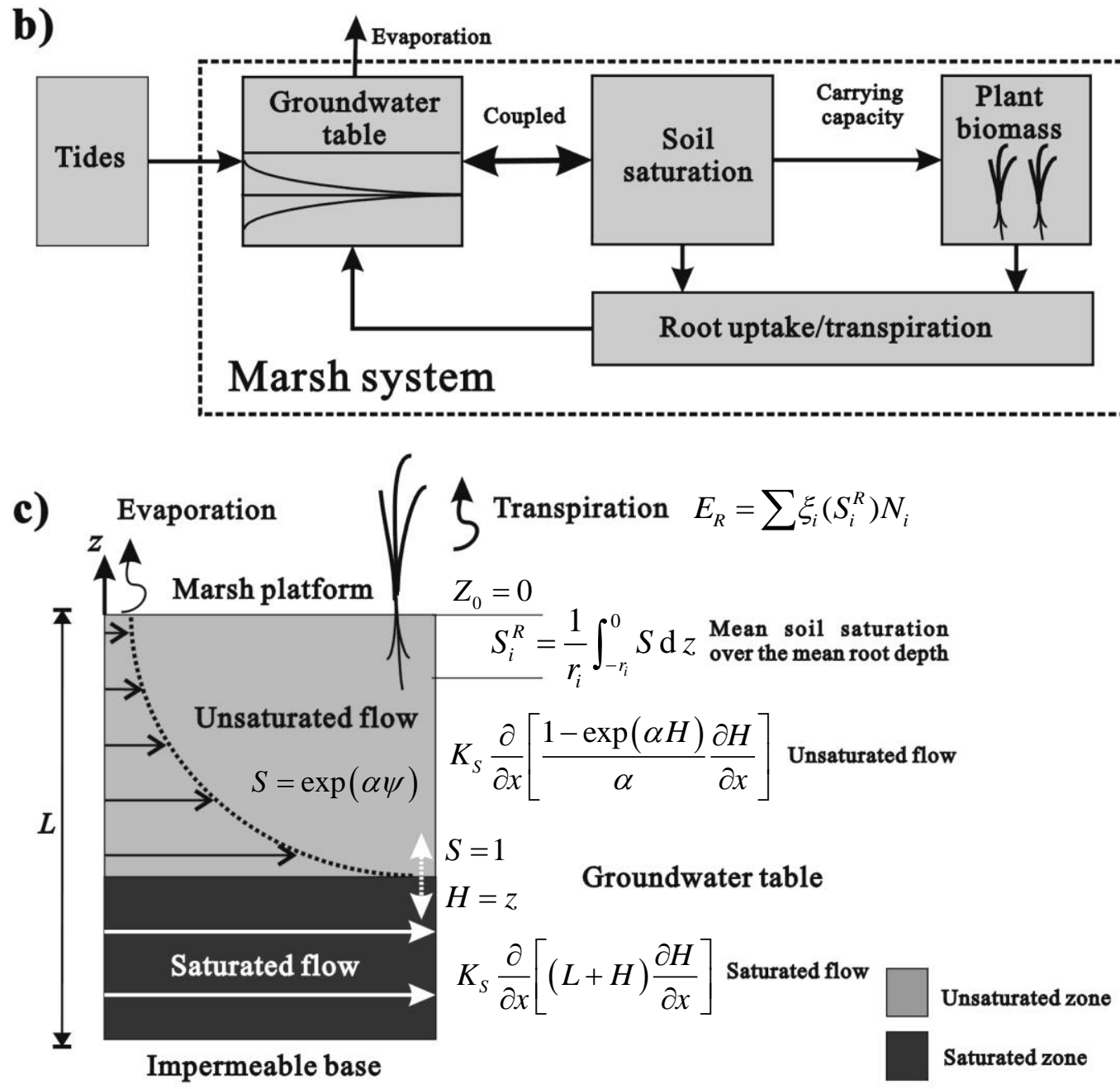

Figure 1. Schematic diagrams of (a) a cross-creek marsh section subjected to the influence of spring-neap tides; (b) process coupling; and (c) a numerical model integrating saturated and unsaturated flow, including the effect of transpiration. 
a)

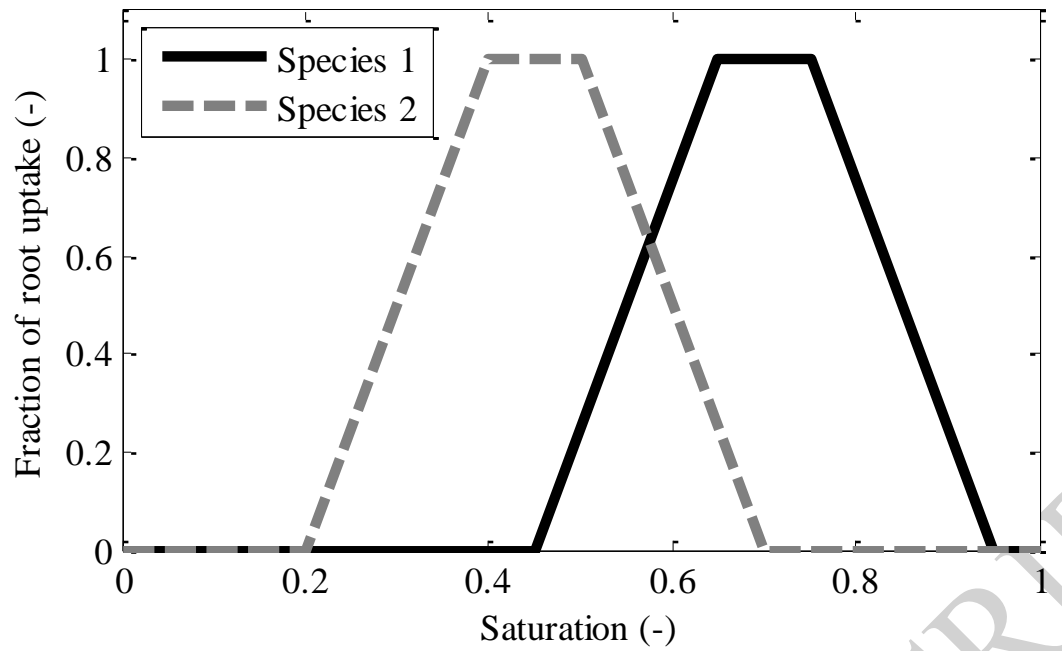

b)

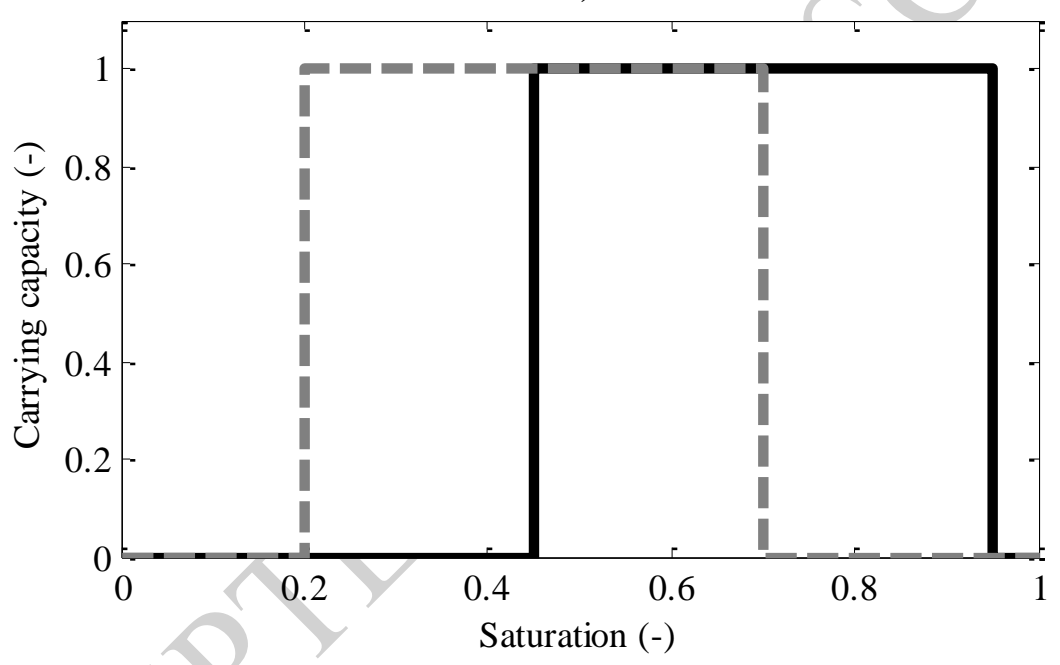

Figure 2. Stepwise linear functions of (a) root water uptake and (b) carrying capacity, depending on the soil-water saturation. 
a)
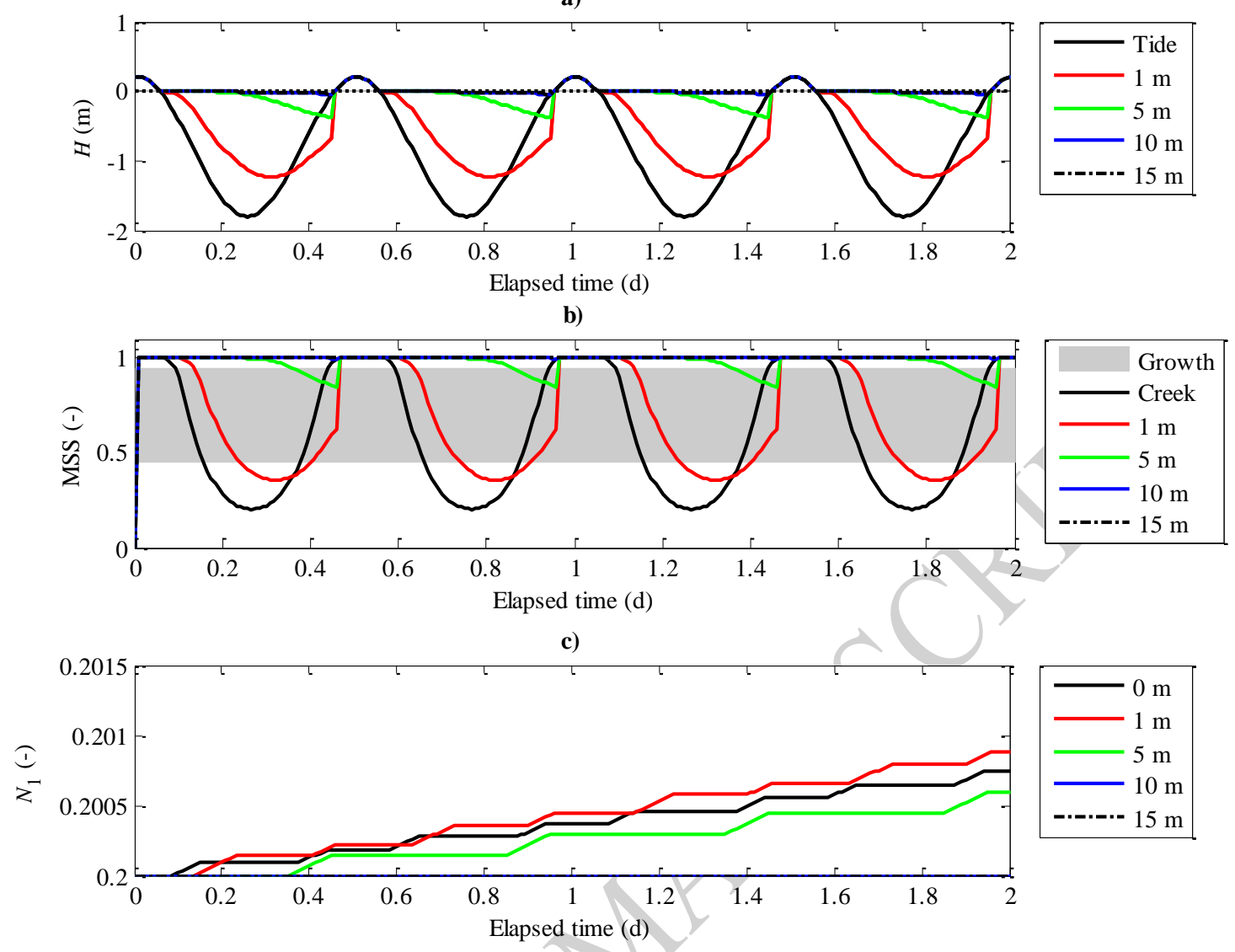

Figure 3. (a) Local watertable fluctuations $(H)$, (b) associated mean soil-water saturation (MSS) over the mean root depth and (c) local biomass ( $N_{1}$ for Species 1$)$. Distances from the creek bank are given in the figure legends. All results are for Case 1 (monochromatic tide). Note that during the marsh exposure, the lines for $x=10 \mathrm{~m}$ and $15 \mathrm{~m}$ overlap with the zero line. 
a)

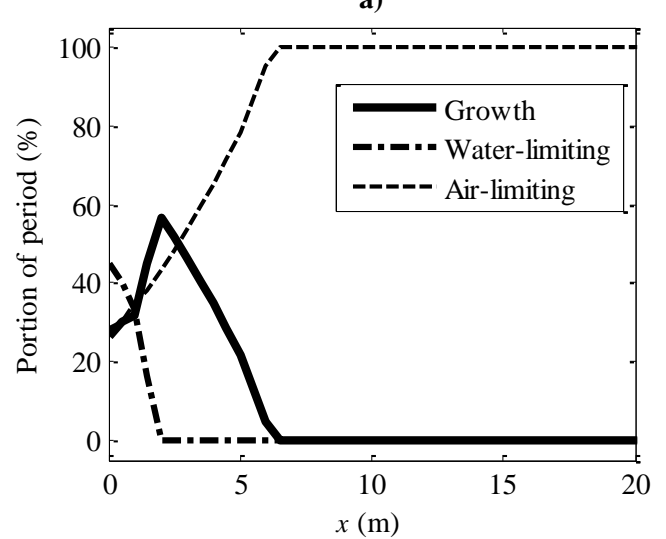

b)

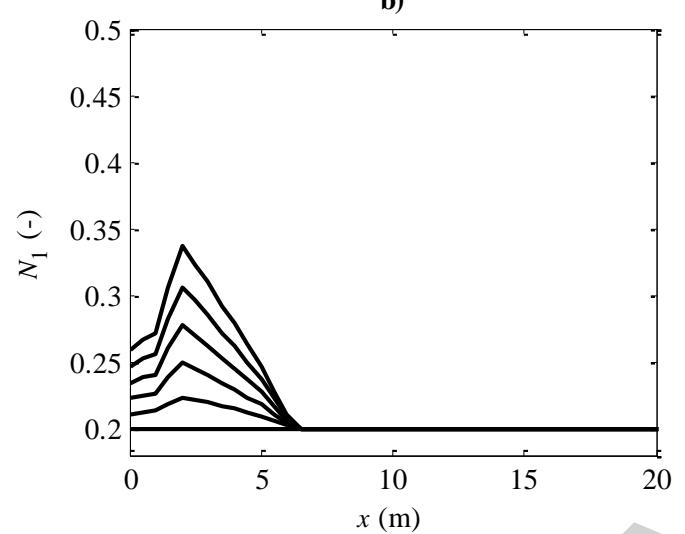

c)

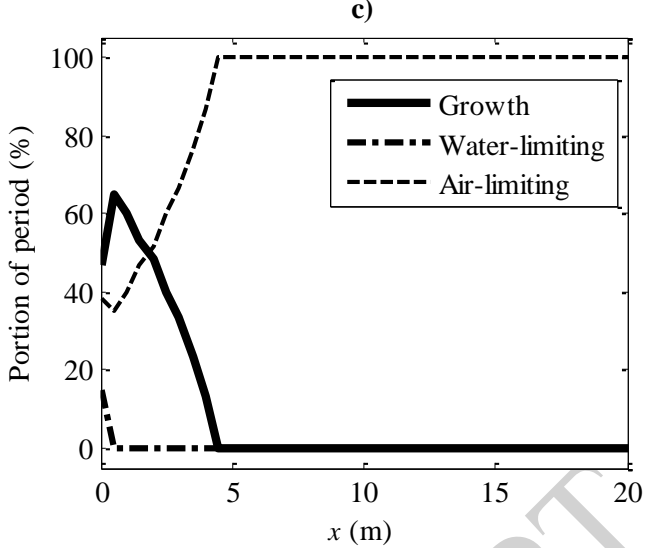

d)

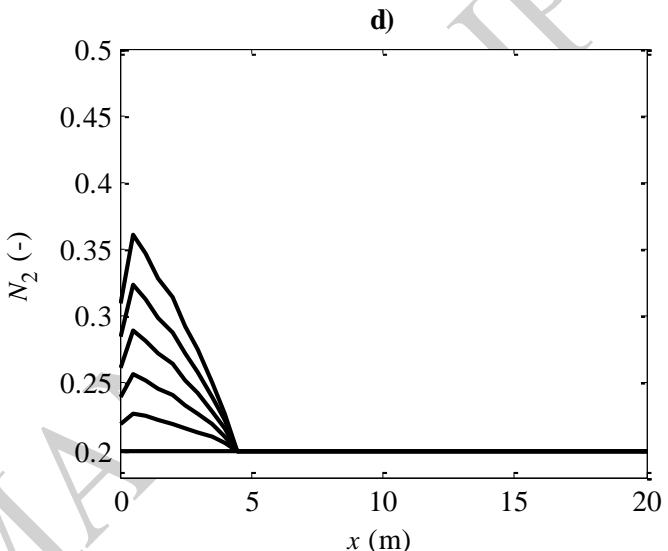

Figure 4. (a and c) Portions of the air-limiting period, water-limiting period and growth period over the semi-diurnal cycle. ( $b$ and d) Spatial biomass variations at different times (from day 0 to 145 , at the interval of two spring-neap tidal cycles). ( $a$ and $b$ ) are for Species 1 and (c and d) for Species 2. All results are for Case 1 considering the monochromatic tide. 
a)

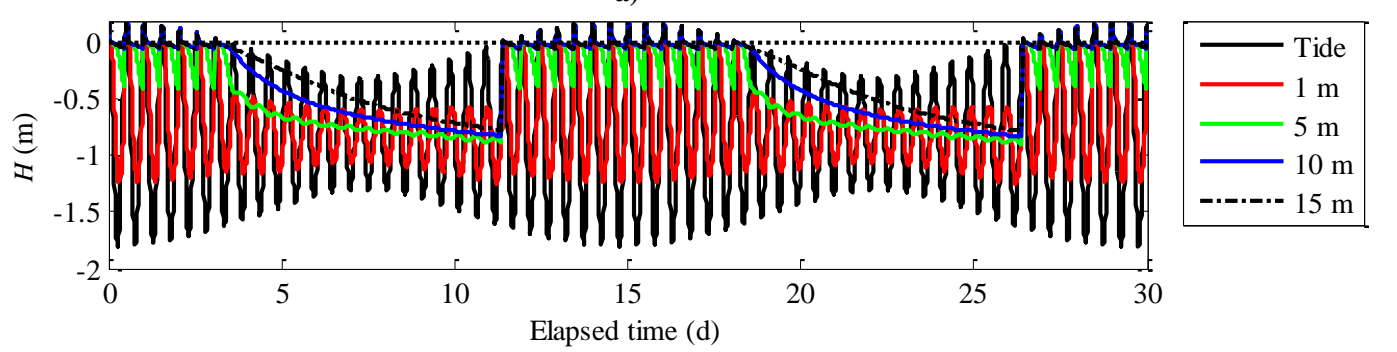

b)
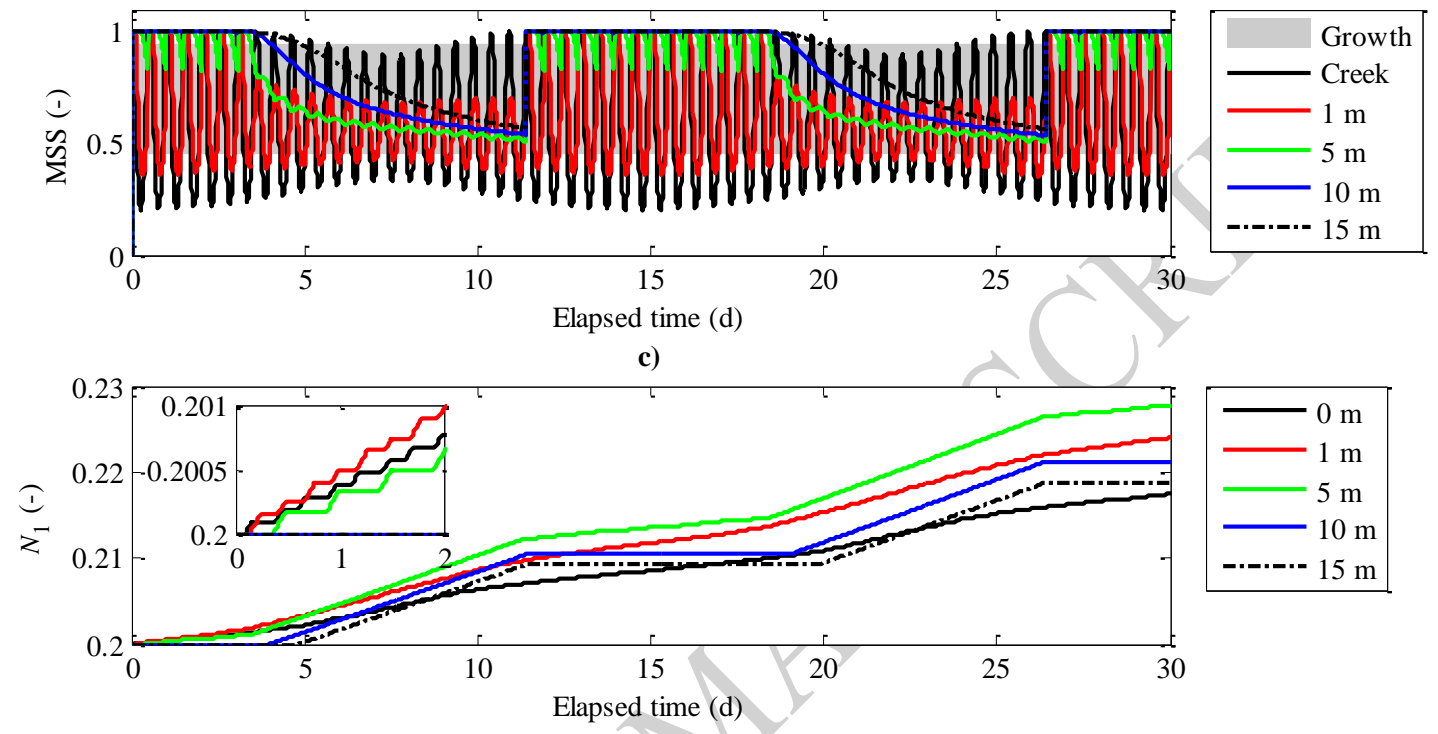

Figure 5. (a) Local watertable fluctuations $(H)$, (b) associated mean soil-water saturation (MSS) over the mean root depth and (c) local biomass ( $N_{1}$ for Species 1$)$. Distances from the creek bank are given in the figure legends. All results are for Case 2 (spring-neap tides). For (c), an enlarged image is inserted. 
a)

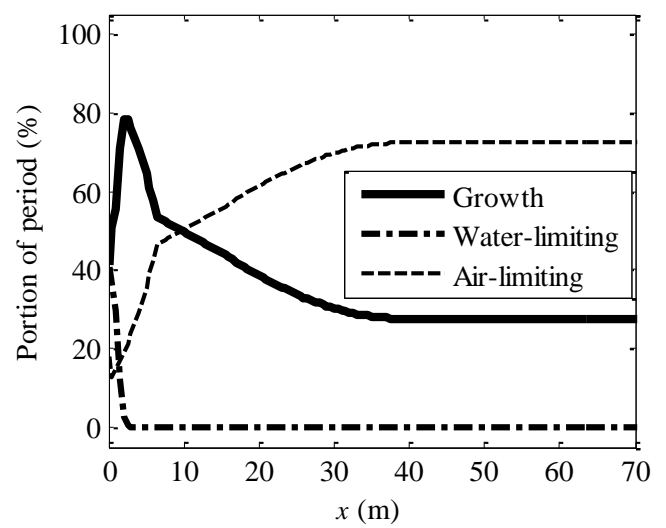

b)

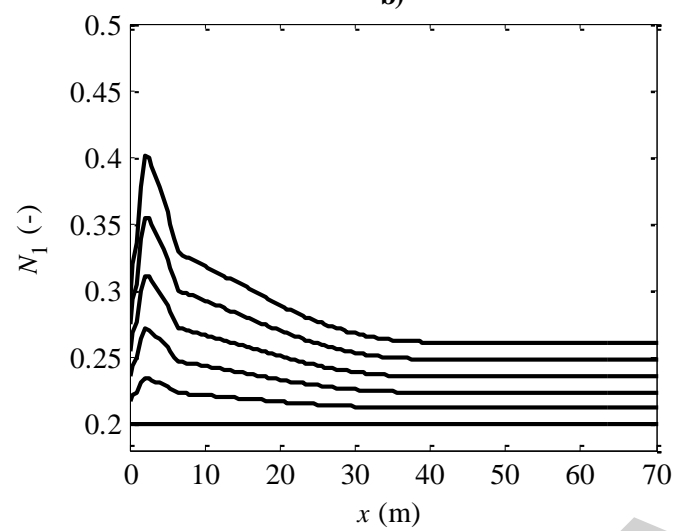

c)

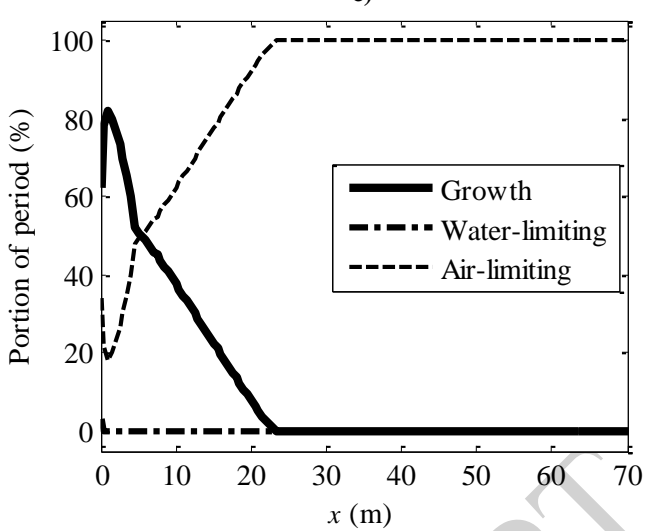

d)

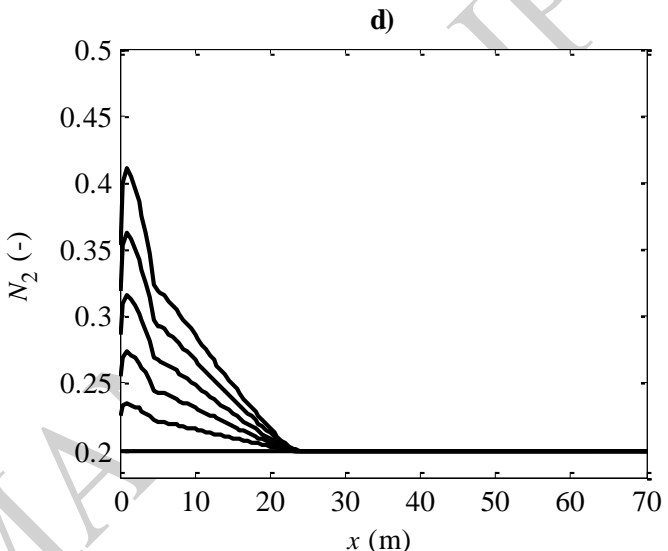

Figure 6. (a and c) Portions of the air-limiting period, water-limiting period and growth period over the spring-neap tidal cycle. ( $b$ and d) Spatial biomass variations at different times (from day 0 to 145, at the interval of two spring-neap tidal cycles). (a and b) are for Species 1 and (c and d) for Species 2. All results are for Case 2 considering spring-neap tides. 
a)

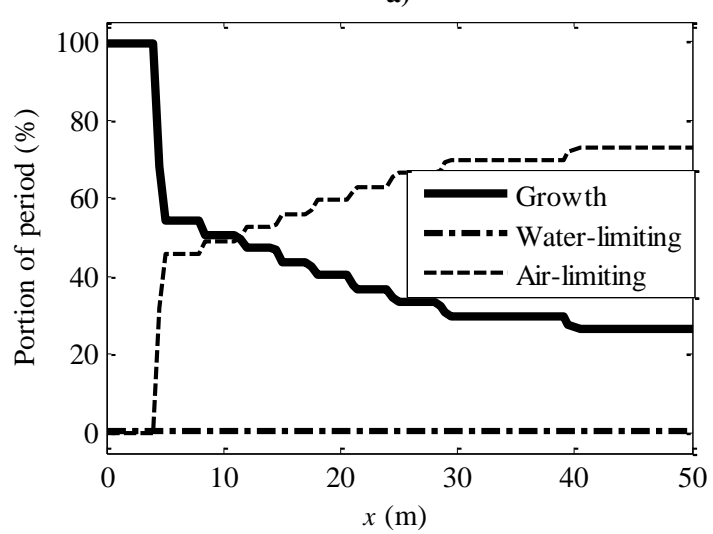

b)

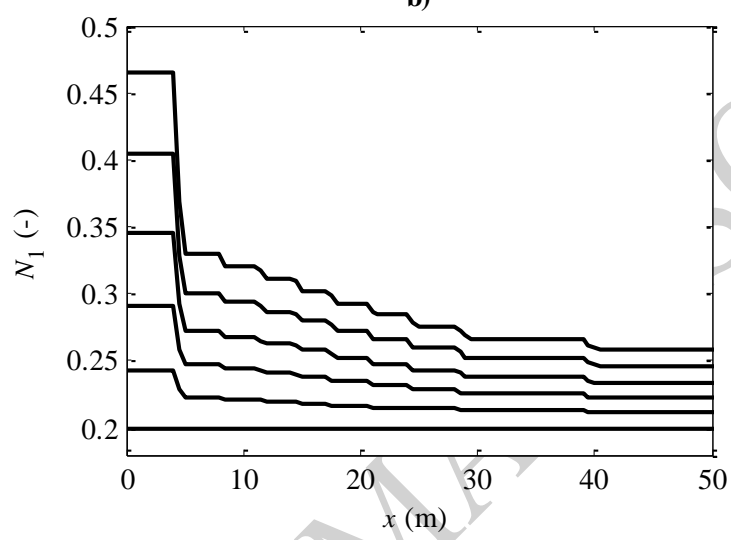

Figure 7. (a) Portions of the air-limiting period, water-limiting period and growth period over the spring-neap tidal cycle. (b) Spatial biomass variations at different times (from day 0 to 145, at the interval of two spring-neap tidal cycles). Results are for Species 1 in Case 2 considering spring-neap tides. The carrying capacity is determined based on the tidally averaged soil-water saturation. 

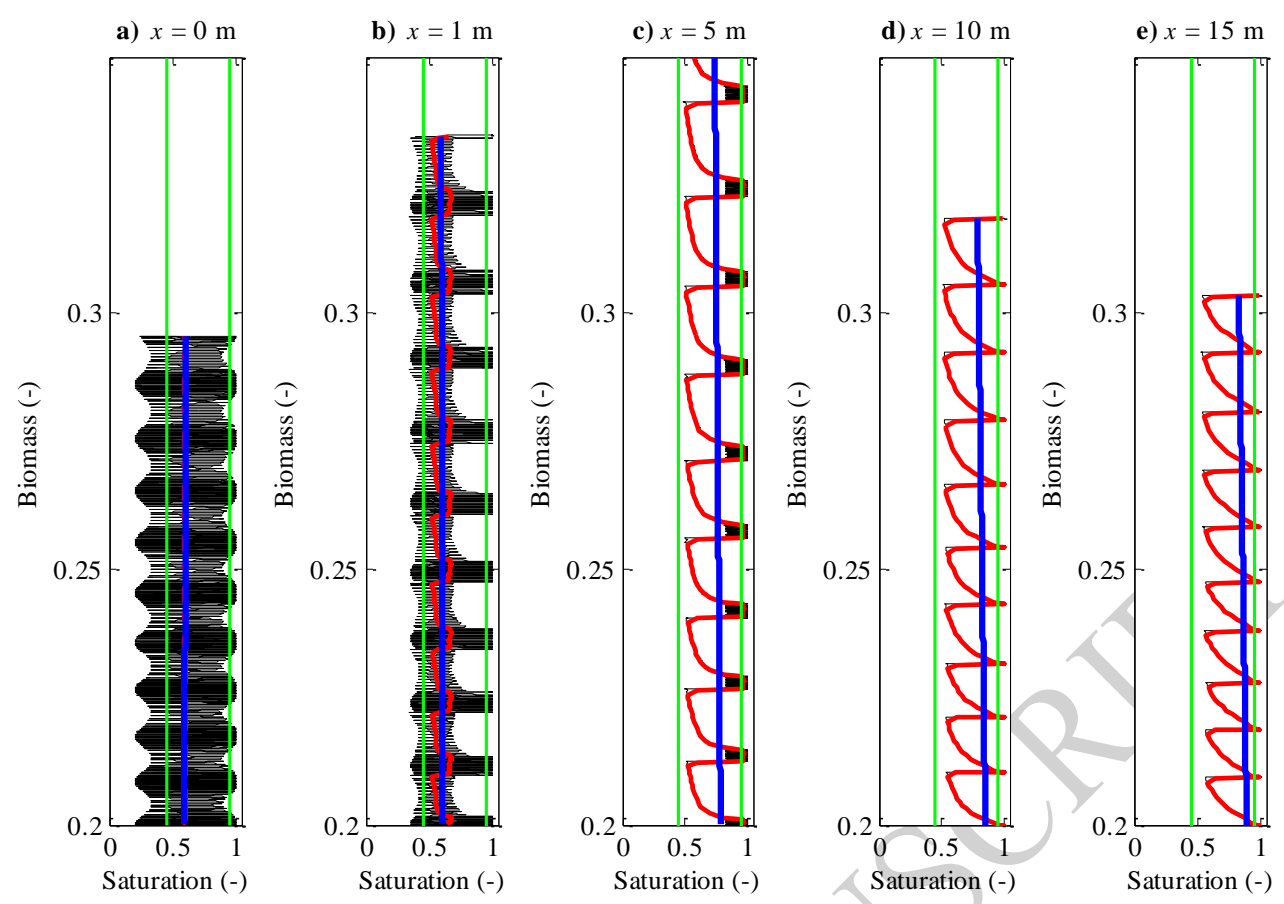

Figure 8. Biomass $\left(N_{1}\right)$ versus mean soil-water saturation (black lines) over the mean root depth at different observation points (for Species 1). Locations are given in the figure titles. The red lines are for the tidally averaged results. The blue lines show the fitted linear trends. Two vertical green lines indicate, respectively, the wilting (left side) and anaerobiosis (right side) point. All results are for Case 2 considering spring-neap tides. 


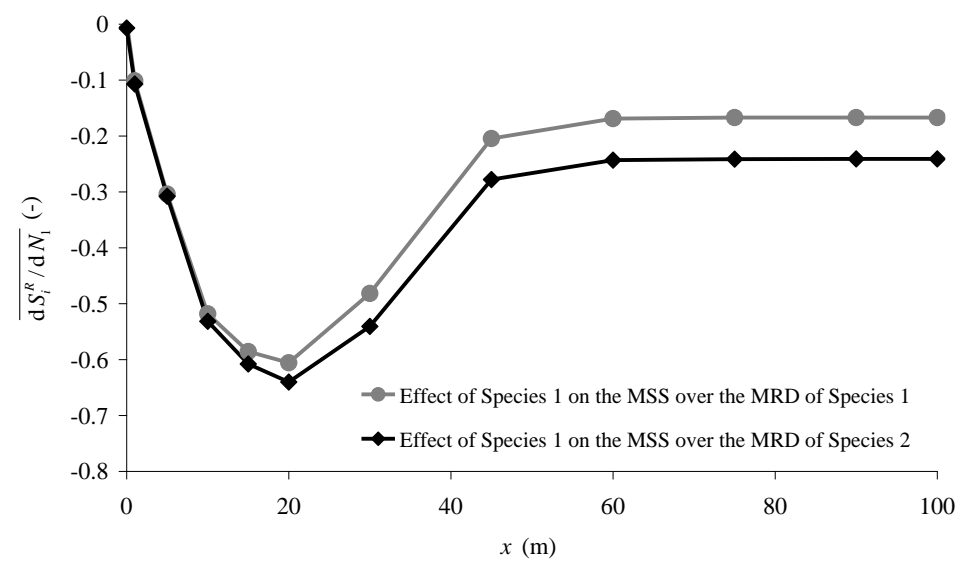

Figure 9. Slopes of the fitted lines shown in Figure 8, i.e., the change of the mean soil-water saturation (MSS) over the mean root depth (MRD) divided by the increase of plant biomass based on the growth of Species 1. 
a)

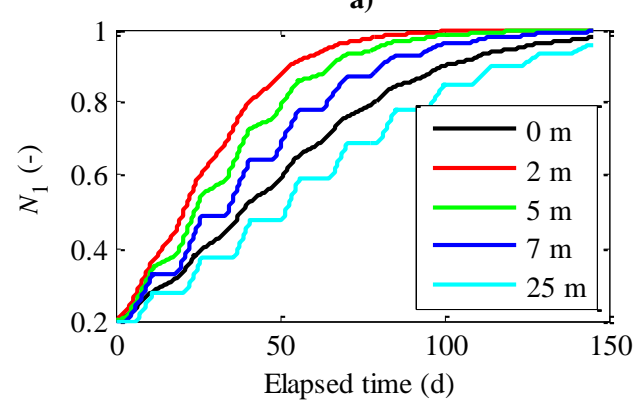

c)

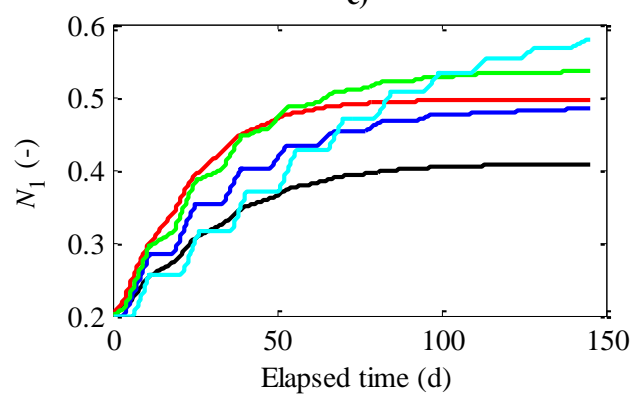

b)

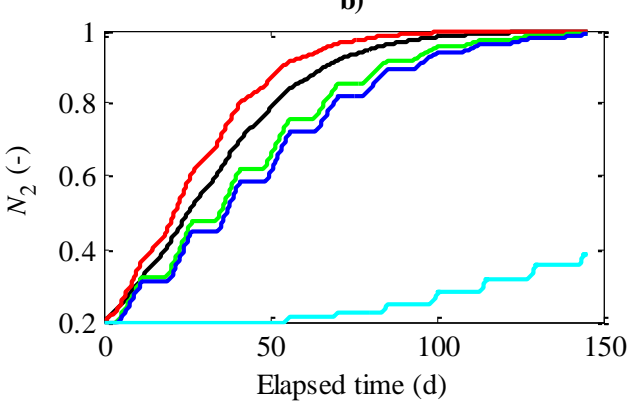

d)

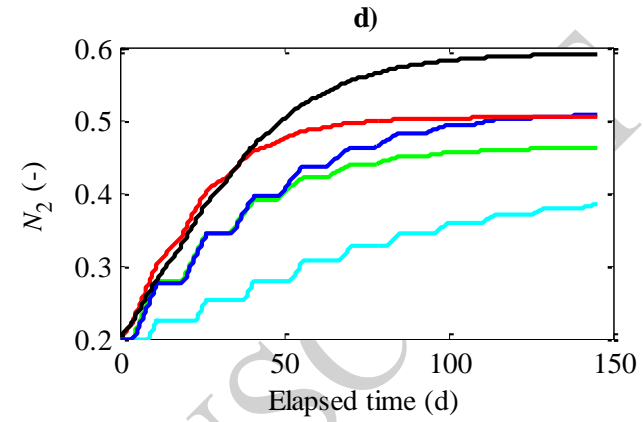

Figure 10. Local biomass variations under the influence of spring-neap tides (growth rate $10^{-6}$ $\mathrm{s}^{-1}$ ). (a) and (c) are for Species 1 and (b) and (d) for Species 2. (a) and (b) show results from the simulation with intra-species competition only, and (c) and (d) from the simulation with intra- and inter-species competitions. The locations of the observation points are indicated by colours as shown in the figure legend. 
a)

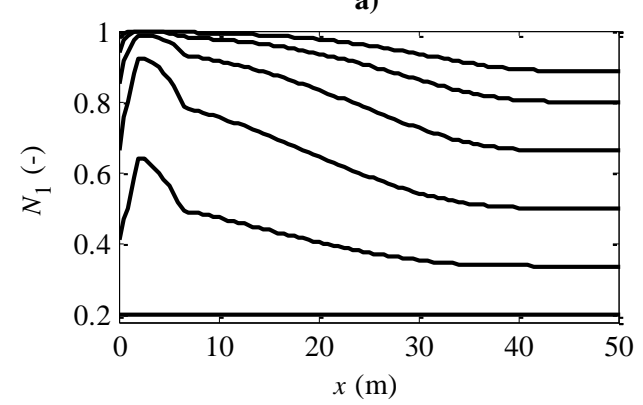

c)

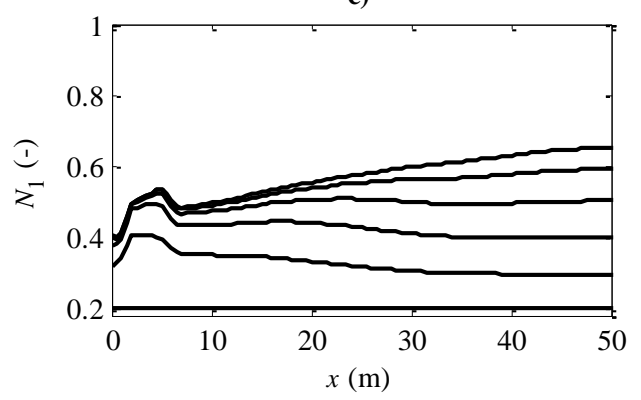

b)

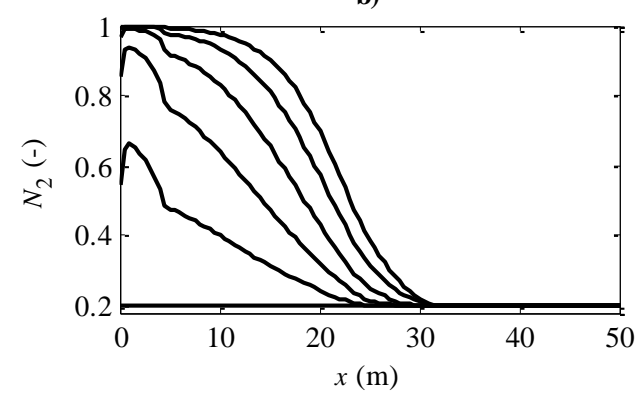

d)

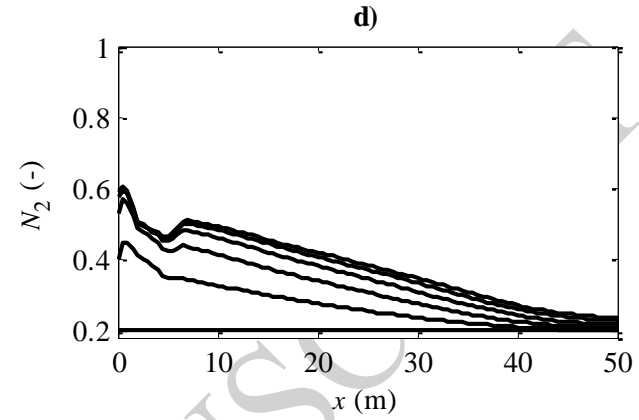

Figure 11. Spatial biomass variations at different times (from day 0 to 145, at the interval of two spring-neap tidal cycles). (a) and (c) are for Species 1 and (b) and (d) for Species 2. (a) and (b) show results from the simulation with intra-species competition only, and (c) and (d) from the simulation with intra- and inter-species competitions. All simulations are based on spring-neap tides and with the larger growth rate $\left(10^{-6} \mathrm{~s}^{-1}\right)$. Note that lines overlap at the equilibrium state. 
a)

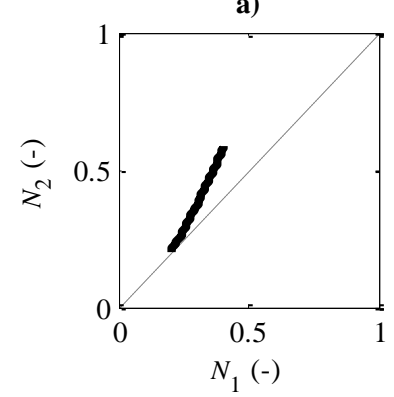

d)

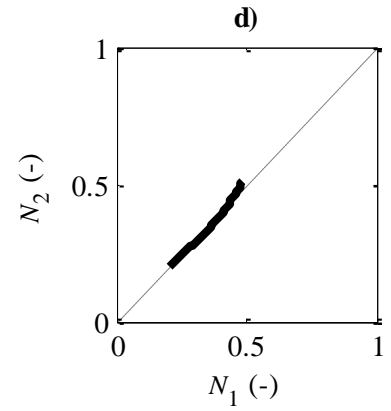

b)

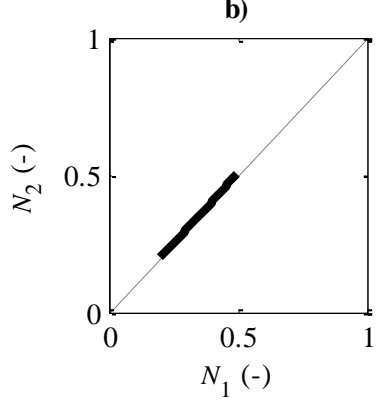

e)

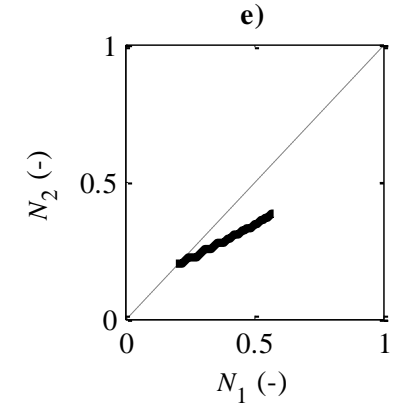

c)
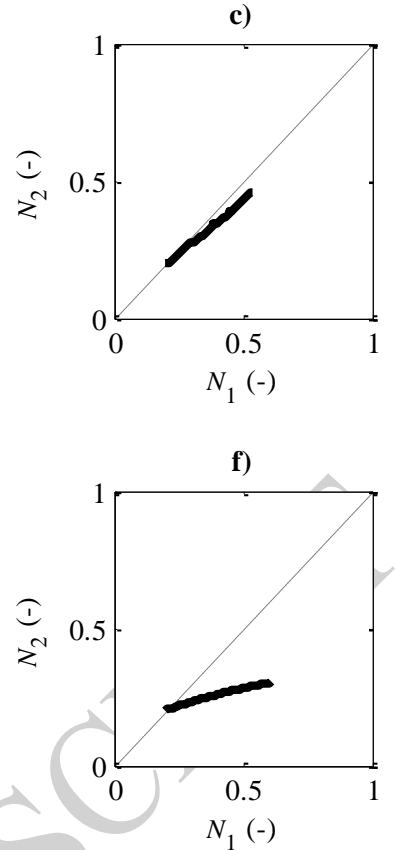

Figure 12. Biomass variation of Species $1\left(N_{1}\right)$ versus biomass variation of Species $2\left(N_{2}\right)$ over ten spring-neap tidal cycles: (a) Creek bank ( $x=0 \mathrm{~m}$ ); (b) $x=2 \mathrm{~m}$; (c) $x=5 \mathrm{~m}$; (d) $x=7$ $\mathrm{m}$; (e) $x=25 \mathrm{~m}$ and (f) averaged biomass across the simulated marsh section. All simulations are based on spring-neap tides and with the larger growth rate $\left(10^{-6} \mathrm{~s}^{-1}\right)$. 

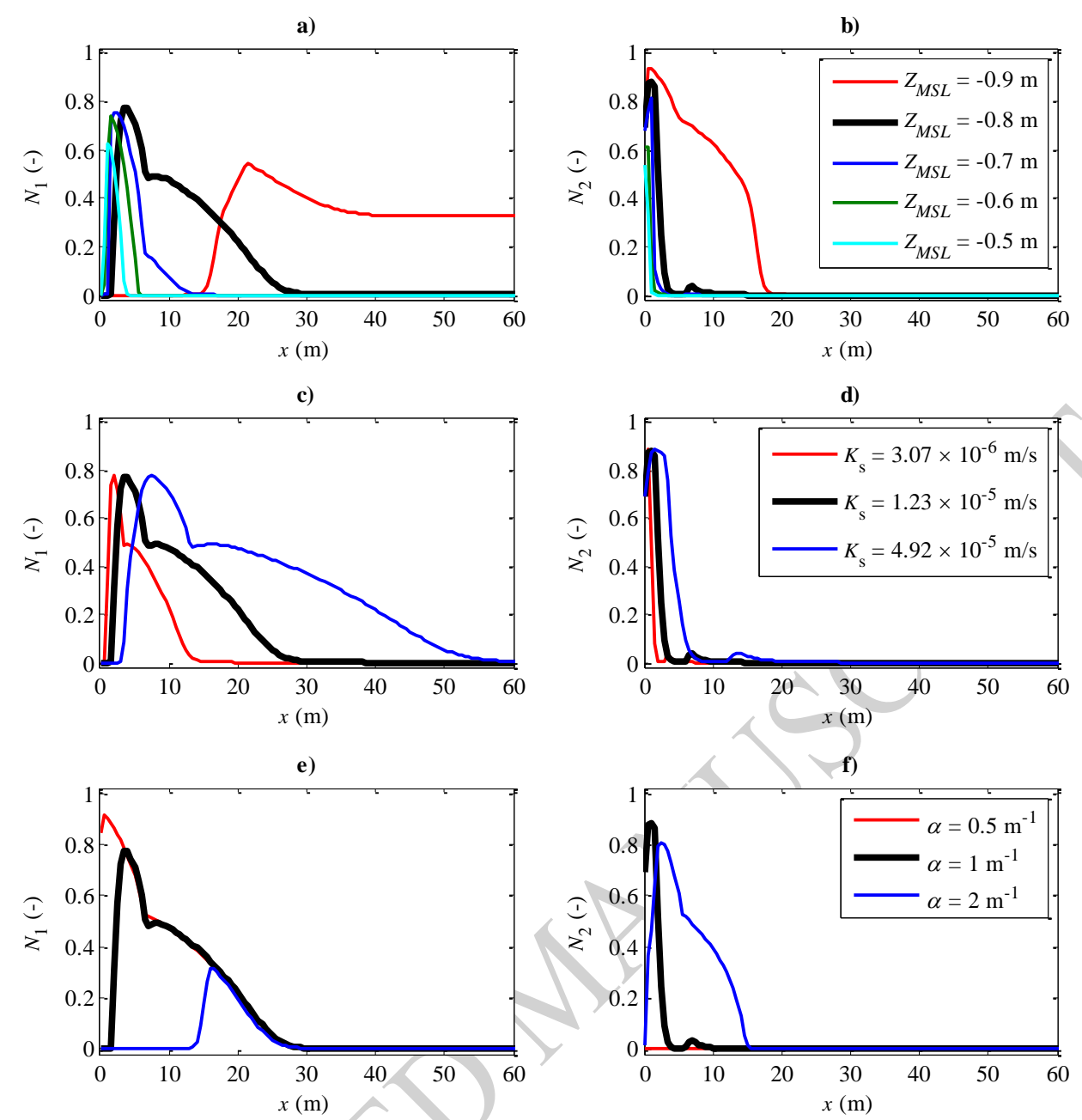

Figure 13. Sensitivity analysis on the equilibrium plant biomass distribution for different (a and b) marsh platform elevations, (c and d) hydraulic conductivities and (e and f) capillary rises. (a, c and e) are for Species 1 and (b, d, and f) for Species 2. All simulations are based on spring-neap tides and with the larger growth rate $\left(10^{-6} \mathrm{~s}^{-1}\right) . Z_{M S L}=-0.8 \mathrm{~m}$ was set for the base case. $Z_{M S L}=-0.7,-0.6$ and $-0.5 \mathrm{~m}$ corresponded with relative decrease of the marsh platform elevation by $0.1,0.2$ and $0.3 \mathrm{~m}$; and $Z_{M S L}=-0.9 \mathrm{~m}$ corresponded with relative increase of the marsh platform elevation by $0.1 \mathrm{~m}$. 

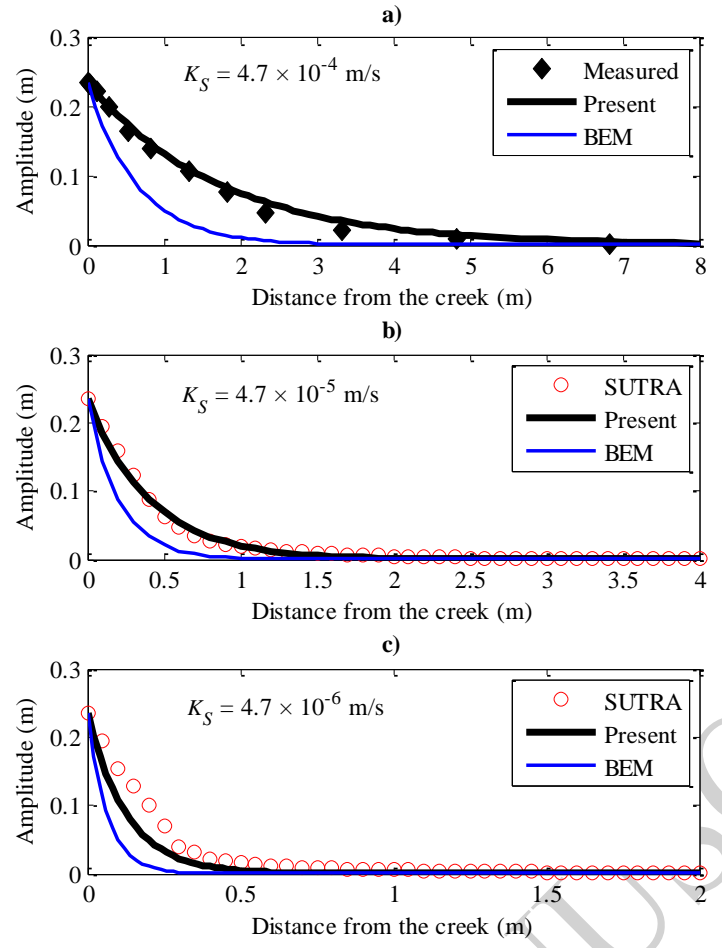

Figure A1. (a) Comparison of amplitudes of watertable fluctuations predicted by the present model (includes capillarity) and the classical Boussinesq equation-based model (BEM, no capillarity) with experimental data [6]. (b) and (c) Comparison of amplitudes of watertable fluctuations predicted by the present model and BEM with simulation results from the Richards' equation-based model (SUTRA [52]). 